\title{
Unsteady-state human-body exergy consumption rate and its relation to subjective assessment of dynamic thermal environments
}

Schweiker, Marcel; Kolarik, Jakub; Dovjak, Mateja; Shukuya, Masanori

Published in:

Energy and Buildings

Link to article, DOI:

10.1016/j.enbuild.2016.01.002

Publication date:

2016

Document Version

Peer reviewed version

Link back to DTU Orbit

Citation (APA):

Schweiker, M., Kolarik, J., Dovjak, M., \& Shukuya, M. (2016). Unsteady-state human-body exergy consumption rate and its relation to subjective assessment of dynamic thermal environments. Energy and Buildings, 116, 164180. https://doi.org/10.1016/j.enbuild.2016.01.002

\section{General rights}

Copyright and moral rights for the publications made accessible in the public portal are retained by the authors and/or other copyright owners and it is a condition of accessing publications that users recognise and abide by the legal requirements associated with these rights.

- Users may download and print one copy of any publication from the public portal for the purpose of private study or research.

- You may not further distribute the material or use it for any profit-making activity or commercial gain

- You may freely distribute the URL identifying the publication in the public portal 


\title{
Unsteady-state human-body exergy consumption rate and its relation to subjective assessment of dynamic thermal environments
}

\author{
Marcel Schweiker $^{\mathrm{a}, \mathrm{b}, *}$ Jakub Kolarik $^{\mathrm{c}}$, Mateja Dovjak ${ }^{\mathrm{d}}$, and Masanori Shukuya ${ }^{\mathrm{e}}$ \\ a Building Science Group, Karlsruhe Institute of Technology, Karlsruhe, Germany \\ ${ }^{\mathrm{b}}$ Heidelberg Academy of Sciences and Humanities, Heidelberg, Germany \\ ${ }^{\mathrm{c}}$ Section for Building Energy, Department of Civil Engineering, Technical University of \\ Denmark, Denmark \\ ${ }^{\mathrm{d}}$ Chair for Buildings and Constructional Complexes, Faculty of Civil and Geodetic \\ Engineering, University of Ljubljana, Slovenia \\ ${ }^{\mathrm{e}}$ Laboratory of Building Environment, Tokyo City University, Yokohama, Japan \\ *Corresponding author email: marcel.schweiker@kit.edu
}

\begin{abstract}
Few examples studied applicability of exergy analysis on human thermal comfort. These examples relate the human-body exergy consumption rate with subjectively obtained thermal sensation votes and had been based on steady-state calculation methods. However, humans are rarely exposed to steady-state thermal environments. Therefore, the first objective of the current paper was to compare a recently introduced unsteady-state model with previously used steady-state model using data obtained under both constant and transient temperature conditions. The second objective was to explore a relationship between the human-body exergy consumption rate and subjective assessment of thermal environment represented by thermal sensation as well as to extend the investigation towards thermal acceptability votes. Comparison of steady-state and unsteady-state model showed that results from both models were comparable when applied to data from environments with constant operative temperature. In contrast, when applied to data with temperature transients the prediction of particular models differed significantly and the unsteady-state model resulted in better prediction of mean skin temperature. The results of the present study confirmed previously indicated trends that lowest human body exergy consumption rate is associated with thermal sensation close to neutrality. Moreover, higher acceptability was in general associated with lower human body exergy consumption rate.
\end{abstract}

\section{Keywords}

Exergy analysis; unsteady-state conditions; temperature drifts; Human body exergy consumption rate; thermal sensation; thermal acceptance

\section{Introduction and background}

Exergy analysis clarifies where and how much of exergy, not energy, is consumed in a whole chain of working systems from man-made systems such as heating or cooling systems to human-body systems [1]. It has been applied in various disciplines for qualitative and quantitative analysis of chemical, biological, mechanical, environmental or industrial processes. Use of exergy concept in the built environment was first introduced in the field of solar-energy utilization by [2] and further in building heating systems by [3] and [4]. A next step in application of exergy analysis is the investigation of human body exergy balance under unsteady-state conditions [5]. Most of human body exergy analyses, mostly 
focused mainly on human body exergy consumption rate, have been made with the assumption of steady-state conditions of thermal environment [5-22]. Human body exergy consumption rate determined for steady state thermal conditions will be further abbreviated $E_{x-s t}$ in the present paper. Authors of these studies generally concluded that there is an optimal combination of indoor air temperature and mean radiant temperature can be fined that provides the lowest possible $E_{x-s t}$. In general, exergy consumption rate is proportional to the difference in temperature between the inside and the boundary surface of the system. In the case of a human body, it is the difference in temperature between the body core and skin layer (or clothing surface). Thus exergy consumption rate can be considered as a kind of thermal stress index. This seemed to be valid both for winter and summer conditions. ... The relation between human-body exergy consumption rates $\left(E_{x-s t}\right)$ and subjectively assessed thermal sensation was analysed in the work of Simone et al. [12]. The results showed that the minimum $E_{x-s t}$ was associated with Thermal Sensation Votes (TSV; “vote” in this context means a point of time when particular human subject filled out a thermal sensation scale during the exposure) close to thermal neutrality, tending to the slightly cool side of thermal sensation [12]. Such results suggest that when human body consumes the least of exergy, the human brain assesses thermal neutrality.

However, real human thermal environments can rarely be described as steady-state. Temperature, humidity, air velocity and other thermo-environmental parameters vary both spatially and with time. These variations affect human thermal behaviour and should be taken into consideration when analysing thermal environment in buildings. To account for the aforementioned phenomena, the model of human body exergy balance under transient conditions (further abbreviated as $E_{x}$ ) was developed by Shukuya [1] [46].Unsteady state exergy analysis method is to aim at allowing us to investigate considering interactions between the dynamic processes inside the human body and those in the environment. So far, the studies on unsteady state exergy analysis of the human body and its relation to thermal comfort are very limited. Tokunaga and Shukuya performed unsteady-state human-body analysis for summer cases [24] and for winter cases [23]. In summary, what they found so far is that the exergy consumption rate varies quite sharply with a change of thermal environment with time, to which the human body is exposed. In summer-case analysis, there was a sudden change in the human-body exergy consumption rate right after entering the mechanically airconditioned room, where the air temperature and relative humidity are significantly lower than the outdoor air temperature and humidity, in opposite there was no such change in the case of naturally-ventilated room [24]. In winter, on the other hand, there was no significant difference in the human-body exergy consumption rate between a room with air-heating and the other with floor heating, since these two room spaces were enveloped by thermally-well insulated walls, floor and ceiling. But, as a window was opened for a short period of time, there was an apparent difference in the rate of exergy transfer by convection due to the effect of ventilation with cold air from outside. In the level of thermal insulation of building envelope system were low, then that exergy transfer by convection must have influenced much on the human-body exergy consumption rate and would have led to thermal sensation of “cold”. Since their findings so far were according to a few trial analyses with respect to 
unsteady-state human-body exergy balance were of course not conclusive, a further series of the analyses are necessary.

General aim of the present paper was to deepen insight to the relation between human body exergy consumption and human perception of thermal environment. This was done by comparing human thermal sensation data measured in three laboratory studies [25, 26, 27] with calculated human body exergy consumption rates calculated for the thermal conditions form aforementioned studies. The studies focused on thermal comfort of human subjects exposed to drifts of operative temperature. The work had two main objectives. For the first, two types of models for determination of human body exergy consumption rate, namely the steady state model and the non-steady state model, were compared. For the second, The observed relationship between the TSV and $E_{x}$ or $E_{x-s t}$ analysed statistically analysed. In addition also data for Thermal Acceptability Vote (TAV) were analysed.

\section{Methods}

\subsection{Unsteady-state human-body exergy analysis}

Thermal cognition and perception based on thermal sensation have been usually statistically analysed in relation to measured physical quantities such as room air temperature, mean radiant temperature, operative temperature or outdoor air temperature. In the case of in-vitro experiments, in which a number of subjects are exposed to a controlled chamber that usually have no windows, the subjective votes taken in the experiment are usually investigated in terms of whether or how they are correlated to the measured indoor environmental parameters of the experimental chambers. On the other hand, in the case of in-vivo experiment or field survey, the subjective votes are usually investigated in terms of whether or how they are correlated to the change in outdoor air temperature [55]. These conventional approaches to thermal-comfort study have revealed a lot, but there are still a number of issues that have not yet been fully investigated. One of them is the aspect of heat-transfer mechanism with respect to the $2^{\text {nd }}$ law of thermodynamics; that is, human-body exergy balance. One of the aspects that have become clear is that thermal environments with higher mean radiant temperature and lower air temperature give smaller human-body exergy consumption rate than that with lower mean radiant temperature and higher air temperature, even if the operative temperature is the same in both cases [source].

Another aspect is related to steady-state or unsteady-state calculation procedures. In the trial analyses made by Tokunaga and Shukuya [24], the calculation of body-core and skin-layer temperature was performed exactly following the procedure given by Gagge et al. [42-44]. In this procedure, the body-core and skin-layer temperature values are determined for each of one-minute period with the input of the corresponding indoor mean radiant temperature, air temperature, humidity, and air velocity, although these input variables are assumed to last for one-hour period for the calculation of body-core and skin-layer temperature. This is, in other words, that the calculations made so far were not really an unsteady-state, but a kind of quasiunsteady-state calculation. Therefore, Shukuya [46] reviewed the whole calculation procedure of the body-core and skin-layer temperature and thereby re-developed the calculation method so that it can perform for unsteady-state conditions . 
In order to compare the two approaches, this study applies the quasi-unsteady-state calculation and the unsteady-state calculation to the data sets described below. Therefore, the VBA code developed by Shukuya [46] and used in several studies [45-47] was transferred into code usable with R software [48] (see Appendix A). The results obtained by the R code were compared to the results deriving from VBA code. No differences except those related to a different accuracy in rounding procedures were found.

Then, two versions of the code were developed. The first one, for quasi-unsteady-state calculation, is performing the following procedure:

- For each time step, the indoor environmental, outdoor environmental, and personal variables are taken as input variables in order to calculate skin and core temperature as well as the exergy consumption rate $\left(E_{x}\right)$ as if those conditions were prevailing for 60 minutes. This is done running a for-loop for 60-times.

o For the first loop, the values for the environmental data (indoor and outdoor) and personal data are taken together with assumed values for $\mathrm{T}_{\mathrm{sk}}$ and $\mathrm{T}_{\mathrm{cr}}$ in order to calculate $E_{x}, T_{\text {cr_n }}$, and $T_{\text {sk_n; }}$;

o For the $2^{\text {nd }}$ to $60^{\text {th }}$ loop the same values for environmental data and personal data are used, but for $\mathrm{T}_{\mathrm{sk}}$ and $\mathrm{T}_{\mathrm{cr}}$ the calculated values from the first loop are considered to calculate $E_{x}, T_{\text {cr_n }}$, and $T_{\text {sk_n }}$;

o As output, for each time step, only the values of $E_{x}, T_{c r \_n}$, and $T_{\text {sk_n }}$ for the last run of the loop are taken.

The second version, for unsteady-state calculation, is running as follows:

- For the $1^{\text {st }}$ time step of the data, the calculation is done as described for the first version, i.e. assuming the conditions to be prevailing for 60 minutes (this is called the warm-up period in this manuscript)

- For the $2^{\text {nd }}$ to $\mathrm{n}^{\text {th }}$ time step, the values for environmental data (indoor and outdoor) and personal data for the corresponding time step, i.e. for $2^{\text {nd }}, 3^{\text {rd }}, \ldots \mathrm{n}^{\text {th }}$ time step are taken. In addition, $\mathrm{T}_{\mathrm{sk}}$ and $\mathrm{T}_{\mathrm{cr}}$ stored from the previous time step are used to calculate $E_{x}, T_{c r} n$, and $T_{s k n n}$; i.e. for the $2^{\text {nd }}$ time step, this is the value for tcr and tsk from the $60^{\text {th }}$ loop from the $1^{\text {st }}$ time step. For the $n^{\text {th }}$ time step this is the value from the $n-1^{\text {th }}$ time step.

- $\quad$ Note that for each time step between the $2^{\text {nd }}$ and $n^{\text {th }}$ time step, no further loops are made, i.e. changes to $T_{\text {sk }}$ and $T_{\text {cr }}$ are calculated only by the length of the time interval between the time step in question and the previous time step multiplied with the corresponding signal. Due to such calculation getting unstable in case the time interval is equal or greater than 2 minutes, the code calculates linear interpolated environmental values to form intervals of equal or less than 60 seconds, in case the time interval of original data is greater than 1 minute. E.g. if the time interval of original data is 5 minutes and $\mathrm{T}_{\text {air }}$ is $25.5^{\circ} \mathrm{C}$ in the beginning of this period and $26.6^{\circ} \mathrm{C}$ at the end, the script will create 4 artificial time steps with interpolated values for $T_{\text {air }}$ and the other values and use those for the calculation.

\subsection{Details regarding studies that provided original data sets}

Kolarik et al. [25] studied the influence of operative temperature ramps ranging from $0.6 \mathrm{~K} / \mathrm{h}$ up to $4.8 \mathrm{~K} / \mathrm{h}$ on thermal comfort and office work performance of 52 college age subjects. The 
exposure took place in the climate chamber providing uniform thermal environment, thus air and mean radiant temperatures were equal during both steady state reference exposures and thermal transients - ramps [49]. The study was divided into two phases - the first addressed summer conditions: temperature range $22-26.8^{\circ} \mathrm{C}$ while the second addressed winter conditions: $17.8-25^{\circ} \mathrm{C}$. Only the second phase of the study was included in the present analysis (see Table 1). Air and operative temperature, air velocity, and relative air humidity were logged in 10 seconds intervals at the centre of the chamber $0.6 \mathrm{~m}$ above the floor. The accuracies of the measuring instrumentation were $\pm 0.5 \mathrm{~K}$ for air temperature, $\pm 0.3 \mathrm{~K}$ for operative temperature, $\pm 0.02 \mathrm{~m} / \mathrm{s}$ for air velocity (in the range $0.05-1 \mathrm{~m} / \mathrm{s}$ ). The temperaturehumidity transmitter measured relative humidity with an accuracy of $\pm 2 \% \mathrm{RH}$ in the $0-90 \%$ $\mathrm{RH}$ range. All measurements complied with requirements in and recommendations given in ISO 7726 [50]. Subjects wore their own clothing during all experimental sessions. Garments were selected during preliminary exposures to constant operative temperature of 24.4 and $21.4{ }^{\circ} \mathrm{C}$ (50 \% RH, 2 hours) for the first and the second phase respectively. The water vapour pressure of $1.53 \mathrm{kPa}$, corresponding to $50 \% \mathrm{RH}$ at $24{ }^{\circ} \mathrm{C}$, was maintained constant during all exposures. During the exposures the subjects were performing simulated office work tasks on PC and filling out questionnaires dealing with thermal comfort, air quality and health related symptoms. 7-point thermal sensation interval scale and two-part acceptability scale were used to assess thermal sensation and thermal acceptability respectively. The subjects made thermal sensation assessment twice every hour of exposure.

The study of Toftum et al. [27] was conducted in the same experimental set-up as the study of [25]. However, subjects were allowed to arbitrarily modify their clothing to keep thermal neutrality. The study comprised summer and winter temperature ranges of $22.0-26.8{ }^{\circ} \mathrm{C}$ and $19.0-23.8^{\circ} \mathrm{C}$ respectively. Altogether 25 college age students participated in the study. Subjects performed simulated office work and regularly filled out questionnaires dealing with thermal comfort, air quality and health related symptoms. The questionnaire set was the same as in the case of the study by [25]. In addition, subjects had to indicate every change of clothing using a separate part of the questionnaire. The changes of the clothing insulation were included in the data set used for the present study.

The study of Kitazawa et al. [26] was conducted in the same climate chamber as studies by Kolarik et al. and Toftum et al. The focus was on seasonal differences in human responses to increasing temperature. Experiments were conducted in late summer and winter with altogether 128 subjects (both $<30$ and $>60$ years old, see Table 2). The subjects were exposed to operative temperature ramp in a range $24.0-35.2^{\circ} \mathrm{C}$ at a rate of $3.7 \mathrm{~K} / \mathrm{h}$ (for details see Table 1) as well as to a constant temperature of $24{ }^{\circ} \mathrm{C}$. Subjects were dressed so that their clothing insulation was approx. 0.48 clo. During exposures, the subjects performed two types of performance tests (addition and Tsai-partington test) and assessed thermal sensation (7-point scale), thermal acceptability (two-part acceptability scale), general comfort, acute health symptoms and ability to perform work.

\subsection{Data preparation}

Table 1 summarizes the used studies (for details see section 2.3) in terms of test conditions. 
Table 2 presents a summary of anthropological data for human subject used in the studies. Analysis of the data was conducted in two steps. In the first step $E_{x}$ and $E_{x-s t}$ were calculated for each observation in each analysed data set. Due to the time step in the original measurements, we took the time interval at 10 seconds for the data from Kolarik and Toftum, and at 60 seconds for Kitazawa data.

For the further analysis the number of variables in individual datasets was reduced to following: "data” (indicates original dataset from particular thermal comfort study), "datetime" (time stamp for a particular observation), session (type of exposure - temperature ramp of certain slope or constant temperature condition; unique identifier with respect to each original data set), vote (ordinal number of the TSV and TAV assessment conducted by subjects in each session with respect to each original data set), subject (unique identifier for human subject), TSV, TAV, $T_{0}$ (operative temperature), $E_{x}, E_{x-s t}$ For each data set mean values of continuous variables (TSV, TAV, $T_{0}, E_{x}, E_{x-s t}$ ) were calculated representing arithmetic mean of the variable at each particular vote (see Figure 1). The data for first two TSV were removed from the data sets (see section 4.1 Discussion on methodology).

Each original data set was checked for errors and missing values. Records with missing values were removed. Meteorological data for outdoor temperature and outdoor relative humidity were provided by Danish Meteorological Institute (DMI). Data were measured at DMI's station nr. 0618100 Jægersborg (GPS coordinates 55.7663 12.5263), approximately $3 \mathrm{~km}$ from the experimental facilities where all experiments were conducted.
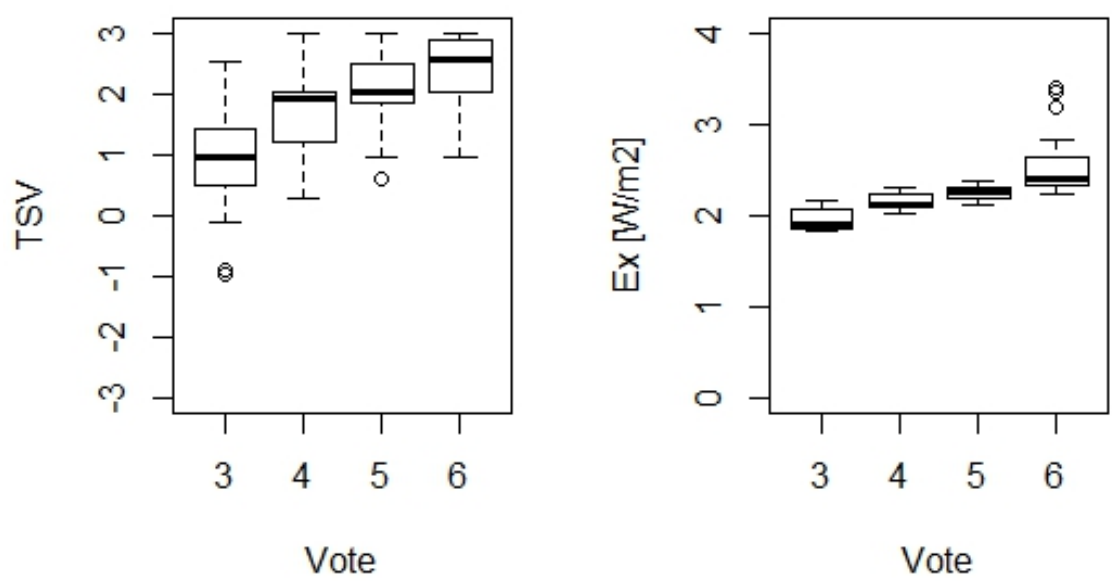

Figure 1 - A box plot summarizing TSV responses (left) and corresponding calculated $E_{x}$ rates (right) for data from the study of Kitazawa et al.[26]

\subsection{Statistical analysis}

Statistical software R version 3.2.2 [48] and RStudio version 0.99.484 [XY] were used to analyse the data. The p-level for rejection of the Null Hypothesis was set to $\mathrm{p}=0.05$. 


\subsubsection{Comparison of $E_{x}$ and $E_{x-s t}$ calculation}

Comparison of $E_{x-s t}$ and $E_{x}$ was done in two steps. First graphically by plotting the mean values of $E_{x-s t}$ and $E_{x}$ against corresponding mean TSV for each analysed dataset.

Consequently, multiple linear regression model was used to analyse differences between $E_{x-s t}=f(T S V)$ and $E_{x}=f(T S V)$ relationships for each individual data set. For example $\mathrm{R}$ function syntax corresponding to the model for data from Kitazawa et al. [26] was (1).

$\operatorname{lm} . k i t a z<-\operatorname{Im}\left(e x \sim t s v^{*}\right.$ model, data=kitazawa.mean.dat $)$

where ex is the predicted value of human body exergy consumption, $t s v$ is a predictor values for human thermal sensation (TSV) and model is a factor indicating whether the data were calculated using steady state or non steady human body exergy consumption model ( $\mathrm{E}_{\mathrm{x}}$ or $\left.E_{x-s t}\right)$. Obtained models were compared with respect to estimated model parameters (intercept, slope and interaction term indicating the effect of change from $E_{x}$ to $E_{x-s t}$ ), their $R^{2}$ (variance explained) values as well as p-values indicating a significance of the model fit. Data from exposure to constant operative temperature by Toftum et al. [27] included two temperature levels. In that particular study, the subjects were exposed to constant temperature of $21.4{ }^{\circ} \mathrm{C}$ as well as to $24.4^{\circ} \mathrm{C}$ (see Table 1). These two exposures were considered separately during regression analysis.

2.5.2 Analysis of general relationship between TSV and human body exergy consumption Linear Mixed Effects Model (LME) approach [52] was used to assess the relationship between $T S V$ and $E_{x}$ as well between $T A V$ and $E_{x}\left(E_{x}=f(T A V)\right.$. Study by Simone et al. [12] showed that the relationship between $E_{x-s t}$ (steady state human body exergy consumption model was used in the study) and TSV could be described by second order polynomial function (2):

$$
E_{x-s t}=0.18 \cdot T S V^{2}+0.22 \cdot T S V+2.83\left(R^{2}=0.68\right)
$$

As Simone et al. [12] did not have access to raw data, relationship described by equation (2) was derived using mean values of thermal sensation votes originating from four thermal comfort studies (see details in [12]). In the present study, second order polynomial function was fitted first to raw data from originating all three investigated studies. The aim was to predict $E_{\mathrm{x}}$ for each particular subject exposed to particular experimental condition. $\mathrm{R}$ function syntax corresponding to the model was (3):

$$
\begin{gathered}
\text { Imer.meta }<-\operatorname{Imer}(e x \sim t s v+I(t s v \wedge 2)+(1 \mid \text { subject }), \text { data=meta.dat, } \\
\text { na.action=na.omit, } R E M L=F)
\end{gathered}
$$

where $e x$ is the predicted value of $E_{x}$, tsv and $t s v^{\wedge} 2$ are predictor values for $T S V$ and $\sim 1$ |subject represents a random effect - within-subject variance, thus the intercept is allowed to vary randomly for each individual subject. The same function was applied to the analysis of TAV. Obtained models were subjected to regression diagnostics including evaluation of normally distributed residuals by inspection of Quantile-Quantile plots (QQ-plots). 
Analysis with LME yielded in estimates of regression coefficients that could be used to define polynomial regression model (4):

$\hat{Y}_{i}=\hat{\beta}_{0}+\hat{\beta}_{1} X_{1 i}+\hat{\beta}_{2} X_{2 i}^{2} \quad i=1 \ldots n$

where $\hat{Y}_{i}$ is the predicted value of $E_{X}$ for $i$ 'th observation, $X_{1 i}$ and $X_{2 i}^{2}$ are predictor values (TSV and TSV $V^{2}$ ) at $i$ 'th observation, $\hat{\beta}_{0}$ is the intercept (predicted value of $E_{X}$ when TSV $=0$ ) and $\hat{\beta}_{1}, \hat{\beta}_{2}$ are representing the regression coefficients. Equation (4) represented fixed effect of TSV on $E_{x}$ estimated from the raw data. $\mathrm{R}^{2}$-values for the complete models and the fixed effects of the models were calculated according to [53].

In addition to the LME model analysis also simple polynomial regression was applied on both raw data (5) and data representing mean for particular votes. $\mathrm{R}$ function syntaxes corresponding to the models were (5) and (6).

Im.meta $<-\operatorname{lm}\left(e x \sim t s v+I\left(t s v^{\wedge} 2\right)\right.$, data=meta.dat $)$

$\operatorname{lm}$. mean $<-\operatorname{lm}(e x \sim t s v+I(t s v \wedge 2)$, data=meta.dat.mean $)$

where $e x$ is the predicted value of $E_{x}$, and $t s v$ and $t s v \wedge 2$ are predictor values for TSV. The model (5) corresponded to the fixed effect from LME model, thus did not account for within subject variation. The model (6) represented approach of Simone et al. [12]. Obtained models were compared with respect to estimated model parameters (intercept and slop), their 95\% confidence intervals and variance explained $-\mathrm{R}^{2}$. The same procedure was performed on the relationship between $T A V$ and $E_{x}$.

Table 1 - Summary of analysed conditions

\begin{tabular}{|c|c|c|c|c|c|c|c|}
\hline $\begin{array}{l}\text { Analysed } \\
\text { study/original } \\
\text { data set }\end{array}$ & $\begin{array}{l}\mathrm{To}^{(1)} / \mathrm{To} \\
\text { range }^{(2)} \\
\left({ }^{\circ} \mathrm{C}\right)\end{array}$ & $\begin{array}{l}\text { Temperature } \\
\text { ramp }(\mathrm{K} / \mathrm{h})\end{array}$ & $\begin{array}{l}\text { Air } \\
\text { humidity } \\
(\%)\end{array}$ & $\begin{array}{l}\text { Clothing } \\
\text { insulation } \\
\text { (clo) }\end{array}$ & $\begin{array}{l}\text { Exposure } \\
\text { duration } \\
\text { (h); } \\
\text { steady } \\
\text { state/ramp }\end{array}$ & $\begin{array}{l}\text { Activity } \\
\text { level } \\
\text { (met) }\end{array}$ & $\begin{array}{l}\text { Air } \\
\text { velocity } \\
(\mathrm{m} / \mathrm{s})\end{array}$ \\
\hline $\begin{array}{l}\text { Kolarik et } \\
\text { al.[25] }\end{array}$ & $\begin{array}{r}(4) 21.4 / \\
19.0- \\
23.8 \text {, } \\
17.8- \\
25.0\end{array}$ & $\begin{array}{l}+0.6,+1.2,- \\
0.6,-1.2\end{array}$ & $\begin{array}{l}\mathrm{p}_{\mathrm{w}}=1.53 \\
\mathrm{kPa}\end{array}$ & $0.9-1.0$ & $\begin{array}{l}6 / 8,6,8, \\
6\end{array}$ & 1.2 & $\begin{array}{l}<0.2 \\
\mathrm{~m} / \mathrm{s}\end{array}$ \\
\hline \multirow[t]{2}{*}{$\begin{array}{l}\text { Toftum et al. } \\
\text { [27] }\end{array}$} & $\begin{array}{r}24.4 / \\
22.0- \\
26.8\end{array}$ & $+1.2,+2.4$ & $\begin{array}{l}\mathrm{p}_{\mathrm{w}}=1.53 \\
\mathrm{kPa}\end{array}$ & $\begin{array}{l}\text { variable } \\
\text { (3) }\end{array}$ & $4 / 2,4$ & 1.2 & $\begin{array}{l}<0.2 \\
\mathrm{~m} / \mathrm{s}\end{array}$ \\
\hline & $\begin{array}{r}21.4 / \\
19.0- \\
23.8\end{array}$ & $+1.2,-1.2$ & $\begin{array}{l}\mathrm{p}_{\mathrm{w}}=1.53 \\
\mathrm{kPa}\end{array}$ & variable $e^{(3)}$ & $4 / 4,4$ & 1.2 & $\begin{array}{l}<0.2 \\
\mathrm{~m} / \mathrm{s}\end{array}$ \\
\hline $\begin{array}{l}\text { Kitazawa et } \\
\text { al. [26] }\end{array}$ & $\begin{array}{r}24 / 24- \\
35.2\end{array}$ & +3.7 & $50 \%$ & 0.48 & $4.5 / 4.5$ & 1.2 & $\begin{array}{l}<0.2 \\
\mathrm{~m} / \mathrm{s}\end{array}$ \\
\hline
\end{tabular}


${ }^{(1)}$ Temperature for reference steady state condition

${ }^{(2)}$ Operative temperature range for ramp/drift exposures

${ }^{(3)}$ Variable clothing

${ }^{(4)}$ Only data from the second part ("winter" conditions) of the experiments by Kolarik et al. were used for analysis 
Table 2 - Basic data for humans subject panels used in analysed experiments

\begin{tabular}{llrrrr}
\hline $\begin{array}{l}\text { Analysed } \\
\text { study }\end{array}$ & Gender & \multicolumn{1}{c}{$\begin{array}{l}\text { Number of } \\
\text { subjects }\end{array}$} & Age [year] & Height [m] & Weight [kg] \\
\hline Kolarik et al. & Male & & & & \\
{$[25]$} & & 26 & $23.8 \pm 3.1$ & $183.4 \pm 7.4$ & $78.7 \pm 10.0$ \\
& Female & 26 & $23.7 \pm 4.9$ & $169.5 \pm 4.8$ & $63.9 \pm 8.3$ \\
& Total & 52 & $23.7 \pm 4.2$ & $176.6 \pm 9.4$ & $71.7 \pm 11.9$ \\
Toftum et al. & Male & & & & \\
{$[27]$} & & 15 & $22.9 \pm 2.1$ & $6183.4 \pm 7.7$ & $74.3 \pm 8.6$ \\
& Female & 10 & $22.8 \pm 1.6$ & $169 \pm 10$. & $56.4 \pm 7.0$ \\
& Total & 25 & $22.9 \pm 1.9$ & $177.4 \pm 11.4$ & $66.8 \pm 11.9$ \\
Kitazawa et & Male & 69 & $48.5 \pm 25.3$ & $180.8 \pm 7.1$ & $78.7 \pm 11.2$ \\
al. [26] & & & & & \\
& Female & 82 & $51.4 \pm 24.7$ & $166.6 \pm 12.9$ & $70.2 \pm 15.7$ \\
& Total & 151 & $49.8 \pm 25.0$ & $174.3 \pm 12.4$ & $74.8 \pm 14.0$ \\
\hline
\end{tabular}




\section{Results}

3.1 Comparison between steady-state and unsteady-state human body exergy consumption model $\left(E_{x-s t}, E_{x}\right)$

The Figure 2 shows the comparison between mean measured and mean predicted $\mathrm{T}_{\mathrm{sk}}$. This shows that in general, both calculation methods are capable of predicting mean $T_{\text {sk }}$ under these controlled condition very precisely. For steady-state conditions (Figure 2a), the mean RMSE-values over all time steps do not differ (RMSE for steady state calculation: .28 .06, for unsteady-state calculation .24 \pm .04 ). For unsteady-state conditions (Figure 2b), the mean RMSE-value for unsteady-state calculation (.28 \pm .02$)$ is significantly lower than that for steady-state calculation (.40土.03).

a)

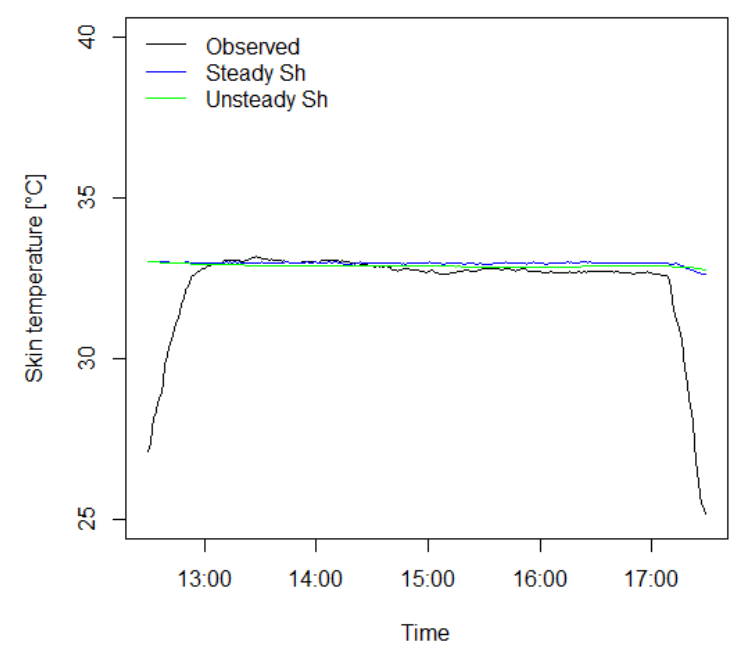

b)

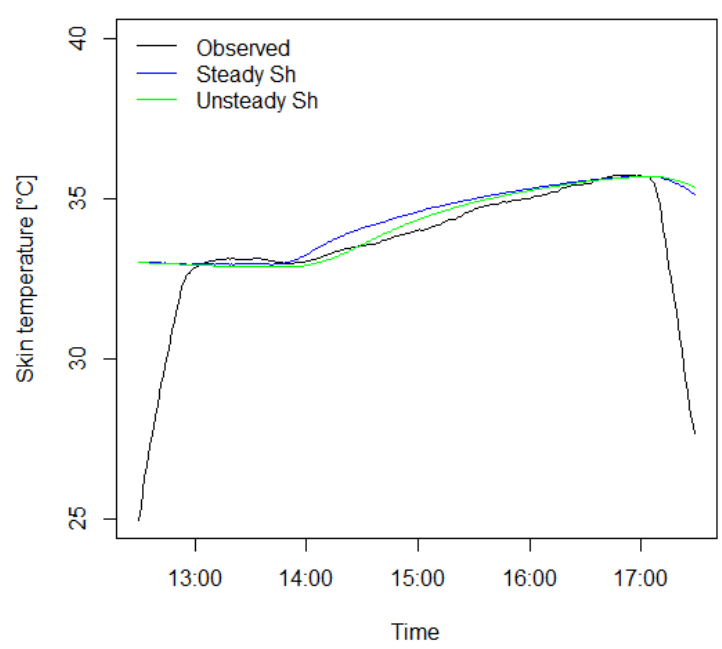

Figure 2 -Mean measured skin temperature in relation to mean predicted skin temperature by steady-state calculation and unsteady-state calculation for Kitazawa data; (a) data from experimental days with constant $T_{o}$, (b) data from experimental days involving $T_{o}$ ramps

The Figure 3 depicts relationships between mean TSV and mean $E_{x-s t}$ as well as mean $E_{x}$ for experimental data from exposures to constant operative temperature (Figure 2a) and operative temperature ramps (Figure 2b). The figure clearly shows that in the case of exposure to constant operative temperature, the use of $E_{x-s t}$ and $E_{x}$ yields in comparable results. On the other hand, use of $E_{x-s t}$ and $E_{x}$ models in the case of conditions with operative temperature ramps results in very different relationships. 
a)

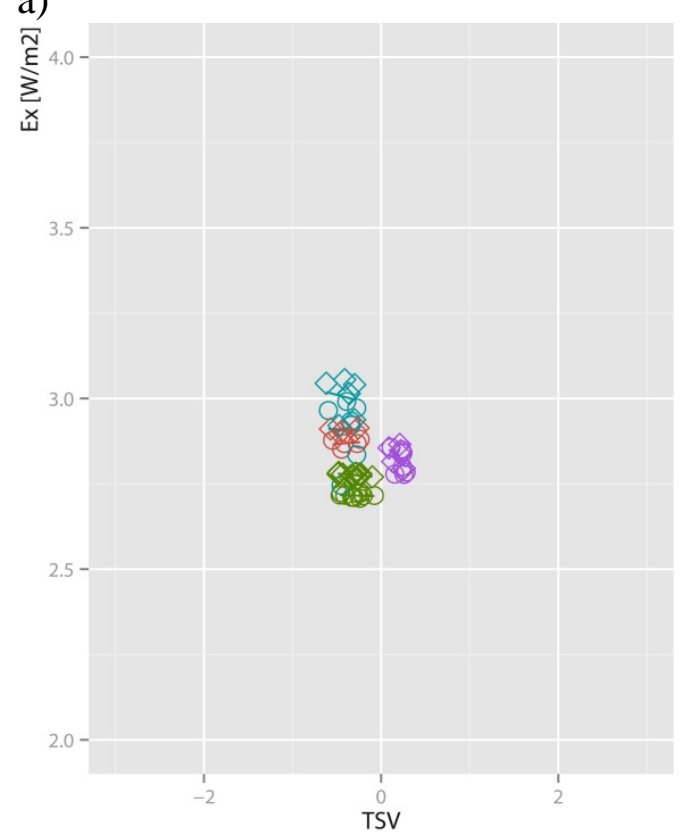

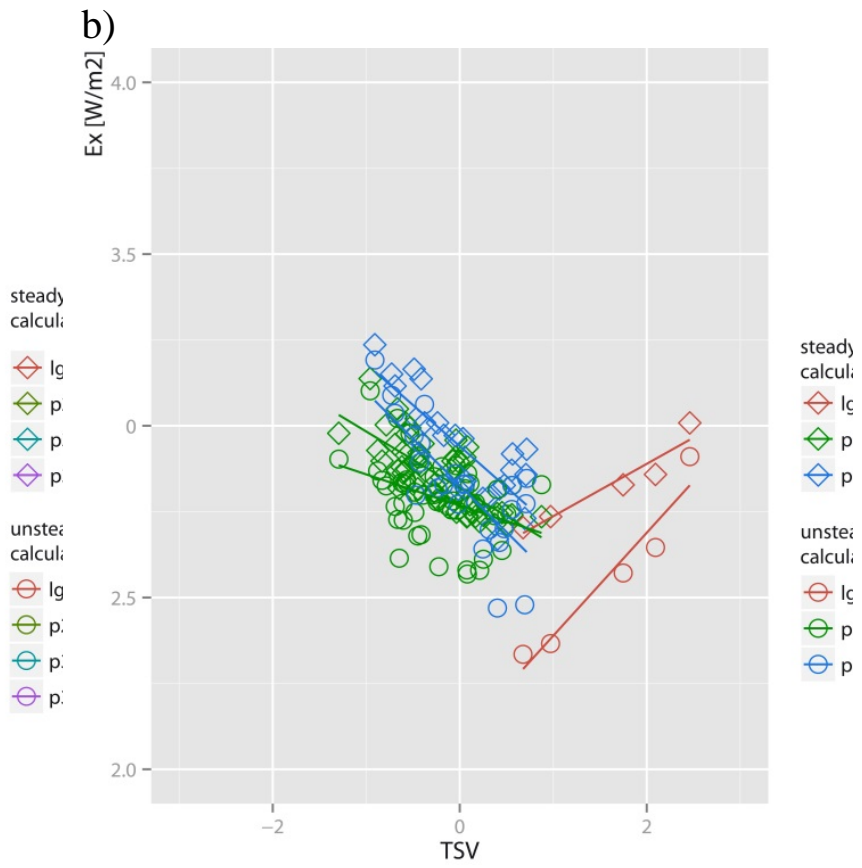

Figure $3-E_{X-s t}$ (diamonds with dashed regression lines) and $E_{X}$ (circles with continuous regression lines) in relation to mean TSV; (a) data from studies involving constant $T_{o}$, (b) data from studies involving $T_{o}$ ramps

This was also confirmed by statistically using multiple linear regression analysis. Its results are summarized in Tables 3 and 4. Table 3 shows that while intercept for linear relationship was significantly different from zero for all studied data sets, the slope of the relationship was not significantly different from zero in any case. The type of exergy model ( $E_{x}$ or $\left.E_{x-s t}\right)$ significantly influenced the intercept of the relationship only for the data by Kolarik et al. [25]. For that data the intercept was significantly higher for $E_{x-s t}$ model; however the increase was very small $\left(0.056 \mathrm{~W} / \mathrm{m}^{2}\right)$. The type of the exergy model did not have significant influence on slope of the relationship in any case. Table 4 indicates that choice of the exergy model played a much higher role when human subjects were exposed to operative temperature ramps. The intercept of the relationship differed significantly between Ex and Ex-st models for all investigated data sets. The slope of the relationship changed significantly in dependency on the exergy model used only in the case of data by Kitazawa et al. [26]. 
Table 3 - Comparison of Ex and Ex-st models for data from exposures to constant operative temperature

\begin{tabular}{|c|c|c|c|c|}
\hline Investigated study & \multicolumn{2}{|c|}{ Kitazawa et al. [26] } & \multicolumn{2}{|c|}{ Kolarik et al. [25] } \\
\hline Regression coefficients & Estimate & p-value & Estimate & p-value \\
\hline Intercept & 2.88 & $<0.0001$ & 2.713 & $<0.0001$ \\
\hline TSV (slope) & -0.020 & 0.642 & -0.008 & 0.593 \\
\hline $\begin{array}{l}\text { Exergy model: } \\
E_{x}>>E_{\text {-st }}\end{array}$ & 0.035 & 0.178 & 0.056 & $<0.0001$ \\
\hline $\begin{array}{l}\text { Interaction: } \\
\text { TSV:Ex- }{ }^{-}-E_{\text {-st }}\end{array}$ & 0.007 & 0.904 & -0.015 & 0.466 \\
\hline $\mathrm{R}^{2}$ of linear model & & 0.85 & & 0.98 \\
\hline $\mathrm{p}$-value of linear model & & 0.007 & & $<0.0001$ \\
\hline
\end{tabular}

Table 4 - Continued

\begin{tabular}{|c|c|c|c|c|}
\hline Investigated study & \multicolumn{2}{|c|}{$\begin{array}{l}\text { Toftum et al. [27] } \\
\text { Temp. level } 21.4^{\circ} \mathrm{C}\end{array}$} & \multicolumn{2}{|c|}{$\begin{array}{l}\text { Toftum et al. [27] } \\
\text { Temp. level } 24.4^{\circ} \mathrm{C}\end{array}$} \\
\hline Regression coefficients & Estimate & p-value & Estimate & p-value \\
\hline Intercept & 2.91 & $<0.0001$ & 2.857 & $<0.0001$ \\
\hline TSV (slope) & -0.007 & 0.287 & -0.202 & 0.375 \\
\hline $\begin{array}{l}\text { Exergy model: } \\
E_{x}->E_{\text {-st }}\end{array}$ & 0.071 & 0.667 & 0.0153 & 0.831 \\
\hline $\begin{array}{l}\text { Interaction: } \\
\text { TSV:E } E_{x}>\text { EX-st }\end{array}$ & -0.062 & 0.881 & 0.00812 & 0.980 \\
\hline $\mathrm{R}^{2}$ of linear model & & 0.33 & & 0.21 \\
\hline p-value of linear model & & 0.236 & & 0.490 \\
\hline
\end{tabular}

Table 5 - Comparison of Ex and Ex-st models for data from exposures to operative temperature ramps

\begin{tabular}{|c|c|c|c|c|c|c|}
\hline Investigated study & \multicolumn{2}{|c|}{ Kitazawa et al. [26] } & \multicolumn{2}{|c|}{ Kolarik et al. [25] } & \multicolumn{2}{|c|}{ Toftum et al. [27] } \\
\hline $\begin{array}{l}\text { Regression } \\
\text { coefficients }\end{array}$ & Estimate & p-value & Estimate & p-value & Estimate & p-value \\
\hline Intercept & 2.088 & $<0.0001$ & 2.768 & $<0.0001$ & 2.827 & $<0.0001$ \\
\hline TSV (slope) & 0.300 & $<0.001$ & -0.091 & $<0.01$ & -0.271 & $<0.01$ \\
\hline $\begin{array}{l}\text { Exergy model: } \\
E_{x}>\text { Ex }_{\text {-st }}\end{array}$ & 0.496 & $<0.01$ & 0.051 & $<0.01$ & 0.114 & $<0.01$ \\
\hline $\begin{array}{l}\text { Interaction: } \\
\text { TSV: } E_{x^{-}}>E X_{\text {-st }}\end{array}$ & -0.147 & 0.038 & -0.073 & 0.061 & 0.032 & 0.593 \\
\hline $\mathrm{R}^{2}$ of linear model & & 0.95 & & 0.39 & & 0.67 \\
\hline $\begin{array}{l}\text { p-value of linear } \\
\text { model }\end{array}$ & & $<0.001$ & & $<0.0001$ & & $<0.0001$ \\
\hline
\end{tabular}

\subsection{Relationship between human body exergy consumption and TSV}


The results of mixed effect model analysis of individual values, linear regression analysis on individual data points, and linear regression analysis for the means of each vote are shown in Table 3. In all analysed cases, the second order polynomial model did not lead to a better prediction based on log-likelihood test. Therefore first order models are presented here. The coefficients for TSV are positive for Kitazawa data and negative for the other two datasets.

Coefficients are significant with $\mathrm{p}<.001$ except for the linear model of Kitazawa data, were it is significant with $\mathrm{p}<0.05$. 
Table 6 - Coefficients, confidence intervals and $\mathrm{R}^{2}$-values for models denoting relationship between TSV and $\mathrm{E}_{\mathrm{x}}$

\begin{tabular}{llrlrlrr}
\hline Model & Dataset & \multicolumn{1}{l}{ Intercept } & Coefficient & \multicolumn{2}{l}{$\begin{array}{l}\mathrm{R}^{2} \\
\text { model }\end{array}$} & \multicolumn{2}{l}{$\begin{array}{l}\mathrm{R}^{2} \text { fixed } \\
\text { effects }\end{array}$} \\
\hline Mixed effect & Kitazawa & 1,870 & $\pm 0,071$ & $+0,189$ & $\pm 0,034$ & 0,43 & 0,24 \\
& Kolarik & 2,750 & $\pm 0,054$ & $-0,0835$ & $\pm 0,016$ & 0,36 & 0,053 \\
& Toftum & 2,810 & $\pm 0,056$ & $-0,174$ & $\pm 0,038$ & 0,22 & 0,11 \\
Linear model & Kitazawa & 1,950 & $\pm 0,054$ & $+0,153$ & $\pm 0,027$ & 0,23 & \\
$\begin{array}{l}\text { on individual } \\
\text { data }\end{array}$ & Kolarik & 2,740 & $\pm 0,013$ & $-0,0742$ & $\pm 0,018$ & 0,052 & \\
& Toftum & 2,810 & $\pm 0,031$ & $-0,16$ & $\pm 0,037$ & 0,11 & \\
Linear model & Kitazawa & 1,600 & $\pm 0,54$ & $+0,341$ & $\pm 0,28$ & 0,9 & - \\
on means & Kolarik & 2,710 & $\pm 0,031$ & $-0,208$ & $\pm 0,062$ & 0,46 & - \\
& Toftum & 2,820 & $\pm 0,06$ & $-0,218$ & $\pm 0,11$ & 0,38 & - \\
\hline
\end{tabular}

\subsection{Relationship between $E_{x}$ and TAV}

The results of mixed effect model analysis of individual values, linear regression analysis on individual data points, and linear regression analysis for the means of each vote are shown in Table 6. In all analysed cases, the second order polynomial model did not lead to a better prediction based on log-likelihood test. Therefore first order models are presented here. The coefficients for TAV are negative for all data sets. Coefficients are significant with $\mathrm{p}<.001$. Figure 4 presents the regression lines with data for the models including mean votes.

Table 7 - Coefficients, confidence intervals and $\mathrm{R}^{2}$-values for models denoting relationship between TAV and $\mathrm{E}_{\mathrm{x}}$

\begin{tabular}{|c|c|c|c|c|c|c|c|}
\hline \multirow{2}{*}{$\begin{array}{l}\text { Model } \\
\text { Mixed effect }\end{array}$} & \multirow{2}{*}{$\begin{array}{l}\text { Dataset } \\
\text { Kitazawa }\end{array}$} & \multicolumn{2}{|c|}{ Intercept } & \multicolumn{2}{|c|}{ Coefficient } & \multirow{2}{*}{ 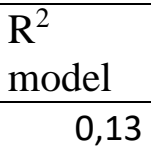 } & \multirow{2}{*}{$\begin{array}{l}\begin{array}{l}\mathrm{R}^{2} \text { fixed } \\
\text { effects }\end{array} \\
0,13\end{array}$} \\
\hline & & 2,190 & $\pm 0,035$ & $-0,164$ & $\pm 0,073$ & & \\
\hline & Kolarik & 2,810 & $\pm 0,057$ & $-0,0839$ & $\pm 0,042$ & 0,31 & 0,0089 \\
\hline & Toftum & 2,940 & $\pm 0,075$ & $-0,257$ & $\pm 0,1$ & 0,15 & 0,032 \\
\hline \multirow{3}{*}{$\begin{array}{l}\text { Linear model } \\
\text { on individual } \\
\text { data }\end{array}$} & Kitazawa & 2,190 & $\pm 0,025$ & $-0,164$ & $\pm 0,042$ & 0,12 & \\
\hline & Kolarik & 2,790 & $\pm 0,02$ & $-0,0641$ & $\pm 0,038$ & 0,0081 & \\
\hline & Toftum & 2,910 & $\pm 0,053$ & $-0,196$ & $\pm 0,087$ & 0,031 & \\
\hline \multirow{3}{*}{$\begin{array}{l}\text { Linear model } \\
\text { on means }\end{array}$} & Kitazawa & 2,090 & $\pm 0,17$ & $-0,636$ & $\pm 0,48$ & 0,91 & \\
\hline & Kolarik & 3,050 & $\pm 0,11$ & $-0,741$ & $\pm 0,27$ & 0,37 & \\
\hline & Toftum & 3,200 & $\pm 0,25$ & $-0,788$ & $\pm 0,49$ & 0,26 & \\
\hline
\end{tabular}




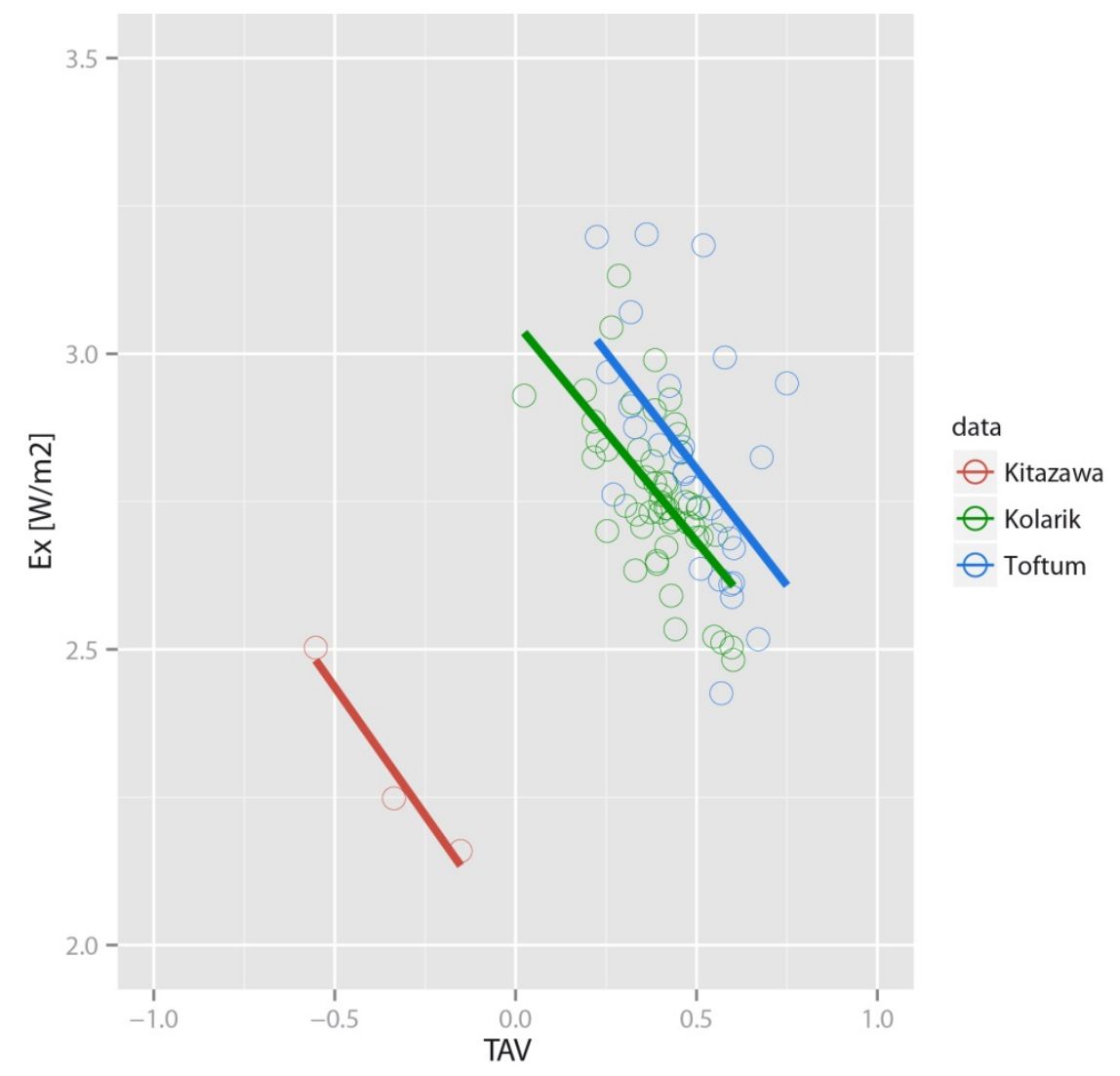

Figure 4 - Polynomial regression model for TAV against Ex according to (8). Circles are presenting mean values for each time of vote at each study. TAV of -1 denotes "unacceptable", +1 “acceptable”.

\section{Discussion}

\subsection{Discussion on methodology}

The first two votes of each experiment were not considered for this paper for the following reasons.

First reason was to eliminate effects due to the decrease of the metabolic rate at the beginning of each exposure. As the metabolic rate of human subjects prior to the laboratory exposure tends to be higher than the one expected during exposure (for all included studies 1.2 met), each of the original studies included pre-exposure of 30 minutes in a constant temperature environment to dissipate any residual metabolic heat resulting from previous activity of the subjects. However, as discussed for example in the paper of Kolarik et al. [25], subject's metabolic rate tended to decrease even after the pre-exposure period. In the studies of Kolarik et al. [25] and Toftum et al. [27] a method for adjustment of TSV votes, originally applied by Knudsen et al. [51], was used to eliminate that effect. Such adjustment was not used in the study of Kitazawa et al. [26]. To preserve consistency of the data, only raw (non-adjusted) data were used in the present study, but the first two votes, having the highest probability to be influenced were removed.

The second reason was the calculation of initial values for unsteady-state $E_{x}$ calculation. It was found that a crucial point in the step from steady-state to unsteady-state calculation is the length and initial values for the warm-up period. Subjects enter into controlled and monitored 
conditions at a certain point. For the studies used for this analysis, nothing was recorded with respect to the time period and environmental conditions subjects experienced before entering the climate chamber. Therefore, a 60-minutes steady-state warm-up period was considered for the calculation of $E_{x}$ within this paper as described in section 2.1. For this warm-up period, the first value of physical data was taken. Still, the comparison between calculated mean $T_{\text {sk }}$ and observed mean $\mathrm{T}_{\mathrm{sk}}$ showed rather big differences for the first 30 minutes of experiments (see Figure 2). Extending the warm-up period to 120 minutes did not have a significant influence on the outcome. The reason for such discrepancy might be related to above mentioned effect of decreasing metabolic rate or to false assumption made for the warm-up period. Therefore, the effect of the length and assumptions for the warm-up period need to be systematically investigated for future studies in order to use all votes.

\subsection{Discussion on results}

Many studies reveal the advantages of unsteady state analysis over steady state analysis. In the study on efficacy of temperature and humidity ramps in energy conservation, [33] showed how air temperature and humidity drifts can offer a useful way to conserve energy for an existing building's environment so that environments do not become totally unacceptable. [24] suggested that natural ventilation together with well-designed solar control and a decrease in internal heat gains is better for human well-being in the built environment. The results of the present study indicate that in the case of environments with fairly constant operative temperatures the two human body exergy models ( $E_{x}$ and $\left.E_{x-s t}\right)$ give comparable results, see Figure 3a and Table 3. The fact that the slope of the relationship between TSV and $E_{x} / E_{x-s t}$ was not significantly different from zero in any of the studied cases suggests that human body exergy consumption rate is independent on thermal sensation under constant operative temperature conditions. Type of the exergy model did not influence slope of the relationship in any of the studied cases. The intercept was influenced by the type of the exergy model only in the case of data from Kolarik et al. [25]. The possible reason the difference in intercepts for $\mathrm{E}_{\mathrm{x}}$ and $\mathrm{E}_{\mathrm{x} \text {-st }}$ data as low as $0.056 \mathrm{~W} / \mathrm{m}^{2}$ turning out significant at $\mathrm{p}<0.0001$ while the difference of $0.035 \mathrm{~W} / \mathrm{m}^{2}$ (data by Kitazawa et al.) being not significantly different from zero is the fact that data by Kolarik et al. were characterizes by least variance from all analysed data sets. Standard deviation calculated on all 11 observations (analysed means) was 0.005 $\mathrm{W} / \mathrm{m}^{2}$ (for both $E_{\mathrm{x}}$ and $\mathrm{E}_{\mathrm{x} \text {-st }}$ ), which is one order of magnitude smaller in comparison to 0.01 $\mathrm{W} / \mathrm{m}^{2}$ Kitazawa et al. and 0.03 respective $0.07 \mathrm{~W} / \mathrm{m}^{2}$ for the two subsets of Toftum et al. (see Table 3). Moreover, the $95 \%$ confidence intervals for the term representing the change in the intercept in the linear regression also confirm the aforementioned consistency of data by Kolarik et al.: $(-0.021,0.090)$ for data by Kitazawa et al.; $(0.042,0.069)$ for data by Kolarik et al. and $(-0.286,0.428)$ respective $(-0.140,0.170)$ for the two subsets of data by Toftum et al. Finally, the sample size has also most probably played its role. There were 11 observations (means for each of the compared exergy models) in comparison to only 5 and 7 for data by Kitazawa et al. and Toftum et al. respectively. In the case of data by Toftum et al. the spread of the data was too big leading to the fact that use of linear regression model would not be appropriate to describe the data (see bottom of Table 3). 
A comparison of $E_{x}$ and $E_{x-s t}$ models applied to data originating from experiments with transient temperature conditions (in the case of the present study operative temperature ramps) depicted in Figure 3 and summarized in Table 4 shows two main outcomes. For the first, there was a significant linear relationship between human thermal sensation vote and corresponding human body exergy consumption rate. This relationship was independent from the exergy calculation model used (both $E_{x}$ and $E_{x-s t}$ ). For the second, the difference in the two studied exergy calculation models was represented by a vertical shift of the regression line rather than a change of its slope. The shift was always negative when considering change from $E_{x-s t}$ to $E_{x}$ model. This means that $E_{x-s t}$ calculation resulted in generally higher human body exergy consumption rate values. results in somewhat unrealistic relationship between human body exergy consumption and TSV. As it can be seen in Figure 3b, when $E_{x-s t}$ model was applied on transient temperature data, the TSV does not have influence on human body exergy consumption (the slope of the relationship becomes flat). This is confirmed by statistical analysis presented in Table 4. So called interaction term in the multiple linear regression model is significant for all studied data sets. It can be seen that the change of the slope due to $E_{x \text {-st }}$ model applied on the data almost exactly levels out the slope of the relationship where $E_{x}$ model was used. For example for data from Kitazawa et al. [26] the slope corresponding to Ex model is 0.341 while when $\mathrm{E}_{\mathrm{x} \text {-st }}$ model is used, the slope changes by -0.286 (the change is statistically significant with $\mathrm{p}=0.017$ ). The fact that TSV would not influence human body exergy consumption under transient temperature conditions does not seem in agreement with fundamental understanding of human body exergy balance [1]. With respect to thermal environment the exergy consumption in the human body is related to the difference between human body core temperature and temperature of skin or for clothed parts of human body temperature of clothing surface. It is obvious such temperature difference occurred in the conditions where human subjects were exposed to operative temperature ramps. At the same time, the aforementioned temperature difference has clear influence on human perception of the environment and thus on subjective thermal sensation [X]. Therefore one can expect a clear relationship between human body exergy consumption and TSV. The validity of such assumption is supported also by the data for study by Toftum et al. [27] presented in Figure 3a. In this study human subjects were asked to adapt their clothing to feel comfortable during the exposure. Therefore even if the operative temperature of their surroundings was constant, the temperature difference between their body core and skin/clothing surface changed due to the adaptation of clothing. Consequently there was a clear relationship between their TSV and calculated $\mathrm{E}_{\mathrm{x} \text {-st. }}$ Figure $3 \mathrm{~b}$ together with Table 4 show clearly that using non steady human body exergy consumption model $\left(E_{x}\right)$ resulted in clear relationship between TSV and exergy consumption. Thus the non steady human body exergy consumption model seems to be appropriate in the case of transient temperature conditions.

Simone et al. [12] concluded that the relationship between human body exergy consumption and thermal sensation could be described by polynomic regression model. This was not confirmed on the data from the present study. When polynomic regression model was fitted to the data, the second order polynomial term was not significantly different from zero .... 
Comparing relationships between TAV and $\mathrm{E}_{\mathrm{x}}$ under operative temperature ramps (Figure 4), major differences can be observed between data by Kitazawa et al. [26] and the two remaining data sets - Kolarik et al. [25] and Toftum et al. [27]. These differences can be probably explained by differences in the clothing level of the human subjects, see Table 1. Figure 5 demonstrates the relationship between clothing level, operative temperature, and $E_{x}$. This observation lead to the decision to analyse each dataset individually and not to use a combined dataset. ...

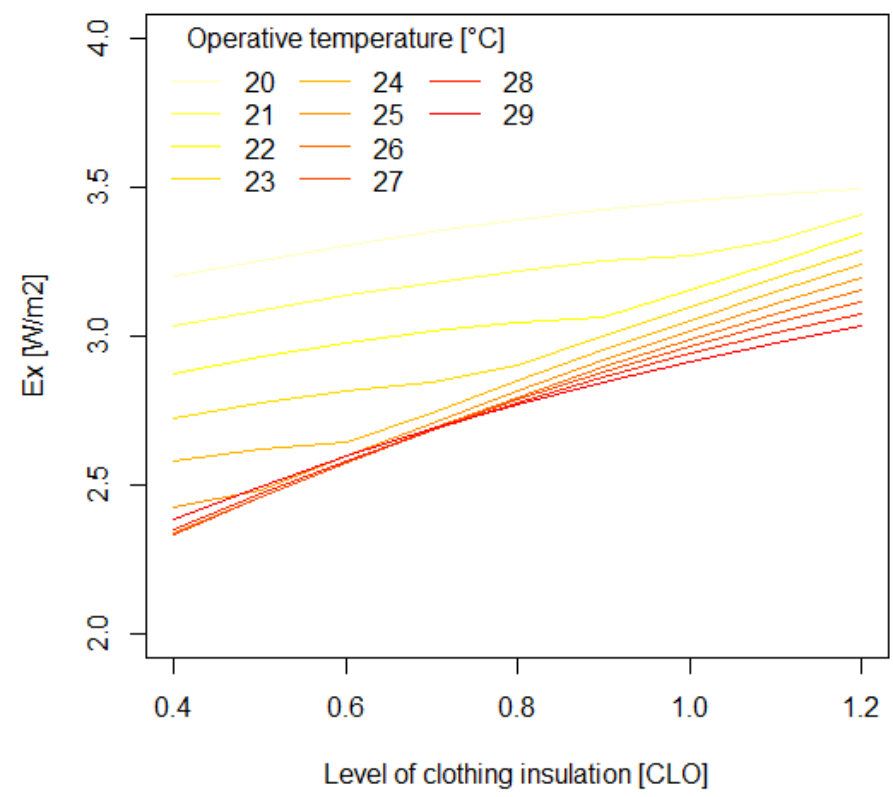

Figure 5 - Relationship between the level of clothing insulation, operative temperature and $\mathrm{Ex}$, assuming air velocity $(.1 \mathrm{~m} / \mathrm{s})$, relative humidity (50\%), outdoor temperature $\left(15^{\circ} \mathrm{C}\right)$, outdoor relative humidity (50\%), and metabolic rate (1.2 MET) to be equal.

Compared to [12], the regression lines shown in our paper for the relationship between TSV and $E_{x}$ differ slightly, but are within the same range. On the one hand, these differences can originate from the assumptions made by [12] for clothing values and metabolic rates. On the other hand, they derive because [12] assumed outdoor conditions equal indoor conditions, while for this study, the prevailing outdoor conditions were used for the calculation of $E_{x}$.

suggest that minimum of Ex is related to slightly warm thermal sensation, while Simone et al.[12] concluded that lowest exergy consumption was related to slightly cool thermal sensation. This difference can be explained again with the different assumption for outdoor conditions plus the data deriving from unsteady state conditions. With the respect to winter conditions, there are several studies that suggest that minimum human body exergy consumption rate is related to higher mean radiant temperature and lower air temperature [1, $6,9]$. For summer conditions, higher temperature first leads to a steep decrease in $E_{x}$ following the increase in skin temperature. However, once sweating starts, the increase in skin temperature slows down due to evaporation and the decrease of $E_{\mathrm{x}}$ slows down as well. At 
even higher temperatures (not observed in normal office spaces, but examined in the study of Kitazawa et al. [26]), the effectivity of sweating does not increase anymore. This leads to an again steeper increase in skin temperature and steeper decrease in $E_{x}$ (Figure 6).
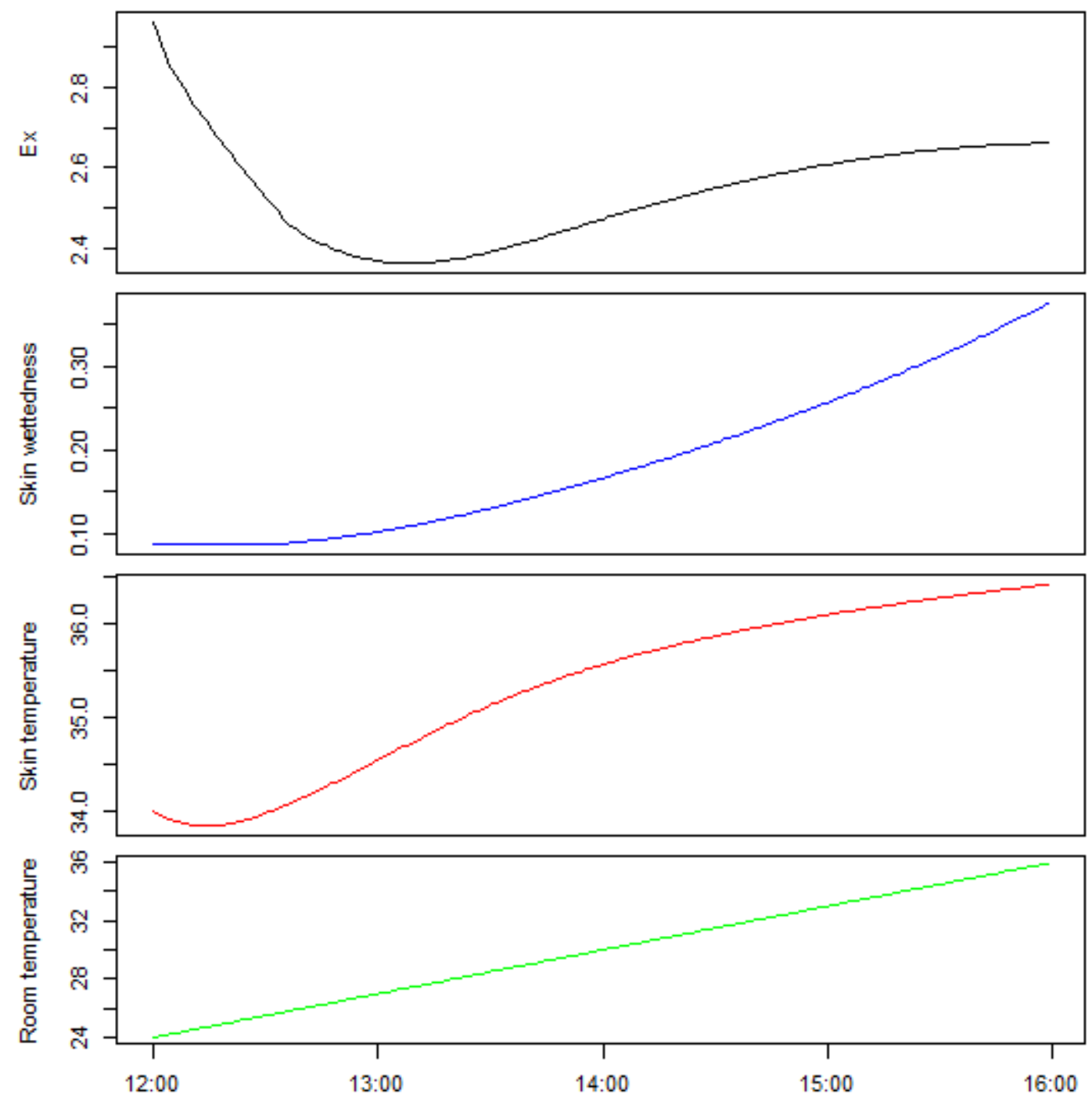

Figure 6 - Example for effect of sweating ( ${ }^{\text {nd }}$ from top), on skin temperature (third from top), and $E_{x}$ (top) for a linear temperature drift from $24^{\circ} \mathrm{C}$ to $36^{\circ} \mathrm{C}$ (bottom); assuming air velocity

$(.1 \mathrm{~m} / \mathrm{s})$, relative humidity $(50 \%)$, outdoor temperature $\left(30^{\circ} \mathrm{C}\right)$, outdoor relative humidity (50\%), clothing level (0.48 clo), and metabolic rate (1.2 met) to be equal

\section{Conclusions}

The present study presents the unsteady state calculation of human body exergy balance and its application to data derived from three experimental campaigns in climate chambers.

Therefore it can be regarded as the next step towards the understanding of the applicability of the exergy balance concept in relationship to subjective thermal sensation. Based on the results, the following conclusions can be drawn:

(1) The result support the assumption, that unsteady-state calculations are necessary for 
unsteady state conditions found in real life settings.

(2) The lowest human body exergy consumption rate is related to a thermal sensation vote close to neutrality, tending to a slightly warm sensation.

(3) Linear relationships between thermal sensation and exergy consumption rate were established including random effects from subjects. The results show medium to high correlation coefficients for the mixed effect models and linear regression models using the mean for each vote.

(4) For the first time, linear relationships between thermal acceptance vote and exergy consumption rate were analysed. Results show lower correlation coefficients for the thermal acceptance votes compared to the thermal sensation vote. However, there are clear linear trends towards a higher acceptance of conditions having a lower exergy consumption rate.

(5) These results support previous studies on the relationship between human-body exergy consumption rate and the assessment of thermal indoor environments.

(6) Future studies need to look at individual parts of the human body exergy balance in order to explore the relationship between exergy consumption rate and thermal sensation.

\section{Acknowledgements}

The collaborative work of this work was supported by funding from the European Union Seventh Framework Programme (FP7/2007-2013) under grant agreement no. PIRG08-GA2010-277061.

The study by Kitazawa et al. [2]was funded by the German Federal Ministry of Economics and Technology (BMWi) with the project ID: 0327241D.

The studies by Kolarik et al. and Toftum et al. [26, 27] were funded by ASHRAE RP-1269, “Occupant Responses and Energy Use in Buildings with Moderately Drifting Temperatures" and the Danish Technical Research Council (STVF) as part of the research program of the International Centre for Indoor Environment and Energy that was established at the Technical University of Denmark from 1998-2007.

Meteorological data were provided by Danish Meteorological Institute, Lyngbyvej 100, 2100 Copenhagen, Denmark.

\section{References}

[1] M. Shukuya, Exergy-theory and applications in the built environment, SpringerVerlag London, 2013, pp. 69-79.

[2] I. Oshida, Lecture on exergy, Solar Energy Institute, Tokyo (in Japanese).

[3] M. Shukuya, Warm exergy and cool exergy, in: Proceedings of Annual Meeting, Building Science Section, Architectural Institute of Japan, 1996, pp. 453-454.

[4] M. Shukuya, A. Hammache, Introduction to the concept of exergy-for a better understanding of low-temperature-heating and high-temperature-cooling systems, VTT TIEDOTTEITA.

[5] M. Shukuya, M. Saito, K. Isawa, T. Iwamatsu, H. Asada, Human-body Exergy Balance and Thermal Comfort, Draft Report for IEA/ECBCS/Annex49, 2010. 
[6] K. Isawa, T. Komizo, M. Shukuya, The relationship between human-body exergy consumption rate and a combination of indoor air temperature and mean radiant temperature, J. Architectural Planning and Environmental Engineering AIJ (570) (2003) 29-35.

[7] M. Shukuya, T. Iwamatsu, H. Asada, Development of human-body exergy balance model for a better understanding of thermal comfort in the built environment, International Journal of Exergy 11 (4) (2012) 493-507.

[8] M. Prek, Exergy analysis of thermal comfort, International Journal of Exergy 1 (3) (2004) 303-315.

[9] M. Shukuya, Exergy concept and its application to the built environment, Building and Environment 44 (7) (2009) 1545 - 1550, the 6th International Conference on Indoor Air Quality, Ventilation \& Energy Conservation in Buildings (IAQVEC 2007), Sendai, Japan, 2831 October, 2007. http://www.sciencedirect.com/science/article/pii/S0360132308001637

[10] M. Shukuya, Comfortable high-performance and low-exergy built environment, in: International-Energy-Agency Programme on Energy Conservation in Buildings \& Community Systems Conference (IEA/ECBCS), Lyon, France, 2006, pp. 893-898.

[11] M. Prek, V. Butala, Principles of exergy analysis of human heat and mass exchange with the indoor environment, International Journal of Heat and Mass Transfer 53 (25) (2010) 5806-5814.

[12] A. Simone, J. Kolarik, T. Iwamatsu, H. Asada, M. Dovjak, L. Schellen, M. Shukuya, B. W. Olesen, A relation between calculated human body exergy consumption rate and subjectively assessed thermal sensation, Energy and Buildings 43 (1) (2011) 1-9.

[13] T. Iwamatsu, H. Asada, A calculation tool for human-body exergy balance, The International Energy Agency, Energy Conservation in Buildings and Community Systems Annex 49 Newsletter (6) (2009) 4-5.

[14] M. Schweiker, M. Shukuya, Adaptive comfort from the viewpoint of human body exergy consumption, Building and Environment 51 (0) (2012) 351 - 360. http://www.sciencedirect.com/science/article/pii/S0360132311003969

[15] M. Prek, V. Butala, An enhanced thermal comfort model based on the exergy analysis approach, International Journal of Exergy 10 (2) (2012) 190-208.

[16] C. E. K. Mady, M. S. Ferreira, J. I. Yanagihara, P. H. N. Saldiva, S. de Oliveira Junior, Modeling the exergy behavior of human body, Energy 45 (1) (2012) 546-553.

[17] Y. Maki, M. Shukuya, Visual and thermal comfort and its relations to exergy consumption in a classroom with daylighting, International Journal of Exergy 11 (4) (2012) 481-492.

[18] M. Dovjak, M. Shukuya, A. Krainer, Exergy analysis of conventional and low exergy systems for heating and cooling of near zero energy buildings, Strojniški vestnik-Journal of Mechanical Engineering 58 (7-8) (2012) 453-461.

[19] X. Wu, J. Zhao, B. W. Olesen, L. Fang, A novel human body exergy consumption formula to determine indoor thermal conditions for optimal human performance in office buildings, Energy and Buildings 56 (2013) 48-55.

[20] C. E. K. Mady, C. Albuquerque, T. L. Fernandes, A. J. Hernandez, P. H. N. Saldiva, J. I. Yanagihara, S. de Oliveira, Exergy performance of human body under physical activities, Energy 62 (2013) 370-378. 
[21] H. Caliskan, Energetic and exergetic comparison of the human body for the summer season, Energy Conversion and Management 76 (2013) 169-176.

[22] M. Ala-Juusela, M. Shukuya, Human body exergy consumption and thermal comfort of an office worker in typical and extreme weather conditions in finland, Energy and Buildings 76 (2014) 249-257.

[23] Shukuya, K. Tokunaga, M. Onoma and Y. Itoh, Calculation of Human-body Exergy Balance for Investigating Thermal Comfort under Transient Conditions, Proceedings of $7^{\text {th }}$ Windsor Conference, Windsor UK, 12-15 April, 2012

[24] K. Tokunaga, M. Shukuya, Human-body exergy balance calculation under un-steady state conditions, Building and Environment 46 (11) (2011) 2220-2229.

[25] J. Kolarik, J. Toftum, B. W. Olesen, A. Shitzer, Occupant responses and office work performance in environments with moderately drifting operative temperatures (rp-1269), HVAC\&R Research 15 (5) (2009) 931-960.

[26] S. Kitazawa, R. Andersen, P. Wargocki, J. Kolarik, M. Schweiker, Seasonal differences in human responses to increasing temperatures, in: Proceedings of Indoor Air 2014, International Society for Indoor Air Quality and Climate (ISIAQ), 2014.

[27] J. Toftum, J. Kolarik, D. Belkowska, B. W. Olesen, Influence on occupant responses of behavioral modification of clothing insulation in nonsteady thermal environments (rp1269), HVAC\&R Research 16 (1) (2010) 59-74.

[28] F. H. Rohles, Temperature \& temperment: A psychologist looks at comfort, ASHRAE Journal 49 (2) (2007) 14.

[29] J. Hardy, J. Stolwijk, Partitional calorimetric studies of man during exposures to thermal transients, Journal of Applied Physiology 21 (6) (1966) 1799-1806.

[30] A. P. Gagge, J. Stolwijk, J. Hardy, Comfort and thermal sensations and associated physiological responses at various ambient temperatures, Environmental research 1 (1) (1967) $1-20$.

[31] F. Rohles, G. Milliken, D. Skipton, I. Krstic, Thermal comfort during cyclical temperature fluctuations, ASHRAE Transactions 86 (2) (1980) 125-149.

[32] L. G. Berglund, R. R. Gonzalez, Application of acceptable temperature drifts to build environments as a mode of energy conservation, ASHRAE Transactions 84 (1) (1978) 110 121.

[33] R. Gonzalez, L. Berglund, Efficacy of temperature and humidity ramps in energy conservation, ASHRAE Journal 6 (1979) 34-41.

[34] F. Rohles JR, J. Laviana, R. Wruck, The human response to temperature drifts in a simulated office environment, ASHRAE transactions 91 (1) (1985) 116-123.

[35] C.-P. Chen, R.-L. Hwang, S.-Y. Chang, Y.-T. Lu, Effects of temperature steps on human skin physiology and thermal sensation response, Building and Environment 46 (11) (2011) 2387-2397.

[36] K. Nagano, A. Takaki, M. Hirakawa, Y. Tochihara, Effects of ambient temperature steps on thermal comfort requirements, International journal of biometeorology 50 (1) (2005) 33-39.

[37] L. Schellen, W. van Marken Lichtenbelt, M. Loomans, J. Toftum, M. De Wit, Differences between young adults and elderly in thermal comfort, productivity, and thermal 
physiology in response to a moderate temperature drift and a steady-state condition, Indoor air 20 (4) (2010) 273-283.

[38] J. Kolarik, J. Toftum, B. W. Olesen, K. L. Jensen, Simulation of energy use, human thermal comfort and office work performance in buildings with moderately drifting operative temperatures, Energy and Buildings 43 (11) (2011) 2988-2997.

[39] Y.-Z. Ji, G.-B. Tu, L. Sun, Effect of air velocity on thermal comfort under thermal environment ramp changing, Transactions of Tianjin University 10 (4) (2005) 291-296.

[40] F. Rohles, W. Wells, The role of environmental antecedents on subsequent thermal comfort, ASHRAE Trans 83 (2) (1977) 21e9.

[41] R. Valancius, A. Jurelionis, Influence of indoor air temperature variation on office work performance, Journal of Environmental Engineering and Landscape Management 21 (1) (2013) 19-25.

[42] A. P. Gagge, J. Stolwijk, Y. Nishi, An effective temperature scale based on a simple model of human physiological regulatory response, Ashrae Transactions 77 (1) (1971) 247262.

[43] A. Gagge, Y. Nishi, R. Gonzalez, Standard effective temperature-a single temperature index of temperature sensation and thermal discomfort, in: Proceedings of the CIB

Commission W45 (human requirements) symposium held at the Building Research Station, 1972, pp. 229-50.

[44] A. P. Gagge, A. Fobelets, L. Berglund, A standard predictive index of human response to the thermal environment, ASHRAE Trans.;(United States) 92 (CONF-8606125-).

[45] M. Shukuya, Indoor-environmental requirement for the optimization of human-body exergy balance under hot/humid summer climate, in: PLEA2015, 9-11 September, 2015.

[46] M. Shukuya, Calculation of human body-core and skin-layer temperatures under unsteady-state conditions-for unsteady-state human-body exergy analysis-, internal report of exergy-research group,, Tech. rep., KIT/TCU (July 2015), DOI:10.1340/RG2.1.3439.4086

[47] K. Isawa, M. Shukuya, Sensitivity analysis on the relationship between human body exergy balance and behavioral adaptation induced by undesirable building envelope cool storage in winter, in: AIJ annual meeting, 4-6 September,, 2015.

[48] R Development Core Team, R: A Language and Environment for Statistical Computing, R Foundation for Statistical Computing, Vienna, Austria, Vienna, Austria, 2012, ISBN 3-900051-07-0. http://www.R-project.org

[49] P. Kjerulf-Jensen, Y. Nishi, H. Graichen, R. Rascati, A test chamber design for investigating man's thermal comfort and physiological response, ASHRAE Trans 81 (Part 1) (1975) 73-82.

[50] ISO 7726, Ergonomics of the thermal environment, instruments for measuring physical quantities, Geneva: International Standard Organization.

[51] H. Knudsen, R. De Dear, J. Ring, T. Li, T. Puntener, P. Fanger, Thermal comfort in passive solar buildings, final report, cec research project: En3s-0035-dk(b), Tech. rep., Technical University of Denmark (1989).

[52] N. M. Laird, J. H. Ware, Random-effects models for longitudinal data, Biometrics (1982) 963-974. 
[53] A. Gelman, J. Hill, Data analysis using regression and multilevel/hierarchical models, 11th Edition, Analytical methods for social research, Cambridge Univ. Press, Cambridge [u.a.], 2009, includes bibliographical references.

[54] ISO 10551, Ergonomics of the thermal environment-assessment of the influence of the thermal environment using subjective judgement scales, Geneva, Switzerland: International Organization for Standardization.

[55] F. Nicol, M.Humphreys and S. Roaf, Adaptive Thermal Comfort - Principles and practice, Routledge, 2012.

[XY] RStudio Team, RStudio: Integrated Development for R. RStudio, Inc., Boston, MA URL http://www.rstudio.com/, 2015. 
Appendix A. R code used to calculated unsteady state human body exergy consumption rate

\# R program to calculate unsteady state human body exergy consumption

\# This is a program for the calculation of human-body core and skin temperatures

\# and also clothing surface temperature based on the two-node model

\# originally developed by Gagge et al.

\# The program has been developed so that it fits the calculation of human-body

\# exergy balance under unsteady-state conditions.

\# The program is based on the Excel version for calculating human body exergy consumption rate developed by Masanori Shukuya

\# 1st ver. Masanori Shukuya 13th February, 2013

\#

\# This program has been further extended to be able to include the human-body exergy balance.

\#

\#

\# This version is for un-steady state exergy calculation.

\#

\# $\quad$ Transformation of VBA-code and Excel procedures into R syntax

\#

Marcel Schweiker May, 2015

\# After loading the necessary functions into $\mathrm{R}$ workspace, the calculation can be called e.g. with the following lines of code:

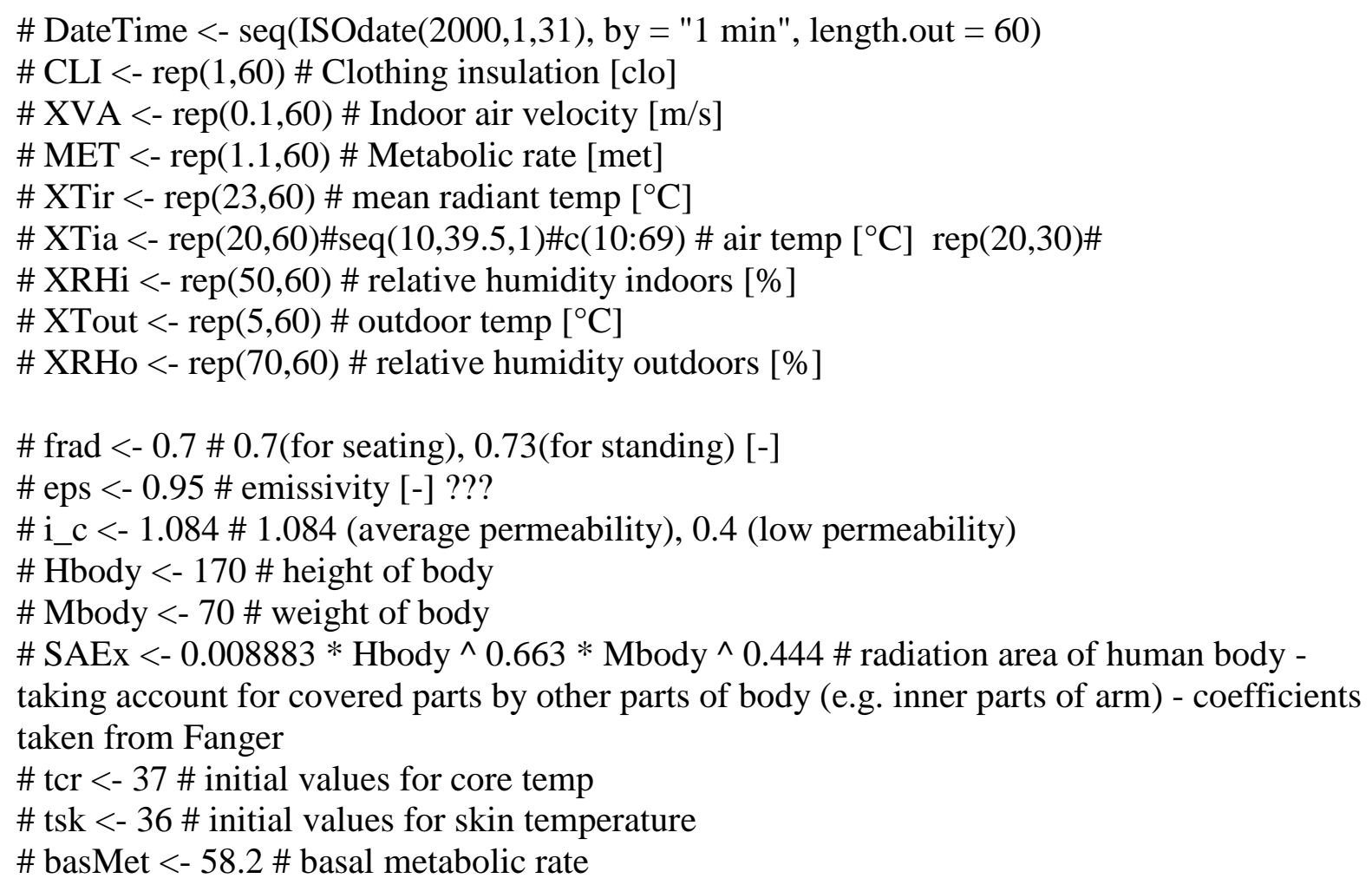


\#\#\#\#\#\#\#! dfForEx should be a dataframe with continuous data preferably with a time interval of less than 2 minutes. In case a time series with intervals greater than 2 minutes is provided, linear interpolation will be done within the analysis to calculate intermediate values

\# dfForEx <- data.frame(DateTime, CLI = CLI, XVA = XVA, XMM = MET, XTir = XTir, $\mathrm{XTia}=\mathrm{XTia}, \mathrm{XRHi}=\mathrm{XRHi}, \mathrm{XTout}=\mathrm{XTout}, \mathrm{XRHo}=\mathrm{XRHo})$

\# Tcr_Tsk_HbEx_balance_unsteady(dfForEx, frad, eps, i_c, SAEx, Mbody, tcr, tsk, basMet) \# X_consumption

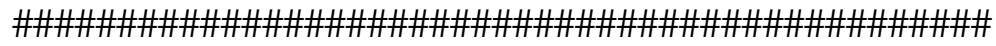 \\ \# definitions of necessary functions

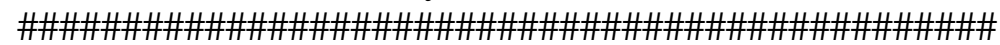

\#\#\#\#\#\#\#\#\# Modul 3

\# Mshiv \# program following function of hypothalamus

\# Calculation of thermal-energy genration by shivering by Stolwijk and Hardy

Mshiv <-function(tcr_set, tsk_set, tcr, tsk) \{

Signal_cr $<-$ tcr_set - tcr;

Signal_cr $<-$ ifelse $($ Signal_cr $<0$, 0, Signal_cr)

Signal_sk $<$ - tsk_set - tsk;

Signal_sk $<$ - ifelse(Signal_sk $<0,0$, Signal_sk)

Mshivx <- $19.4 *$ Signal_cr* Signal_sk

Mshivx

\}

\# Meta_therm: \#Calculation of thermal energy emission rate taking the rate of external work into consideration

Meta_therm <- function(Met, basMet) \{

eff $<-0$

if $($ Met $>=1.4 \&$ Met $<3)\{$

eff $<-0.1$

\} else if (Met $>=3)\{$

eff $<-0.2$

\}

Meta_thermX $<$ - basMet * Met * $(1$ - eff $)$

Meta_thermX

\}

\# Q_load: \#Heat storage rate of human body by Fanger\#s equation

Q_load <- function(Met, PMV, basMet) \{

Q_loadX <- PMV / $(0.303 * \exp (-0.036 *$ basMet * Met $))$

\}

Q_loadX

\#Tsk_req \#Required skin temperature for thermal-energy-wise neutral condition

\#Fanger\#s regression line based on the data collected by Rohles and Nevins 


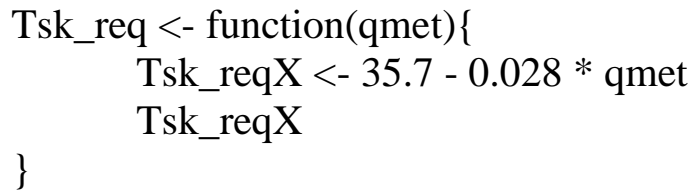

\# Qper_req \#Required resperation rate from the skin surface for thermal-energy-wise neutral condition

\# Fanger\#s regression line based on the data collected by Rohles and Nevins

Qper_req <- function(qmet) \{

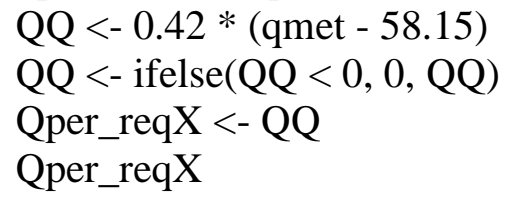

\# Qskin_evap: Thermal energy emission rate by water-vapour diffusion from the skin surface Qskin_evap <- function(qmet, pa) \{

Qskin_evapX <- 3.05*10^(-3)*(5733. - $6.99 *$ qmet - pa)

\}

Qskin_evapX

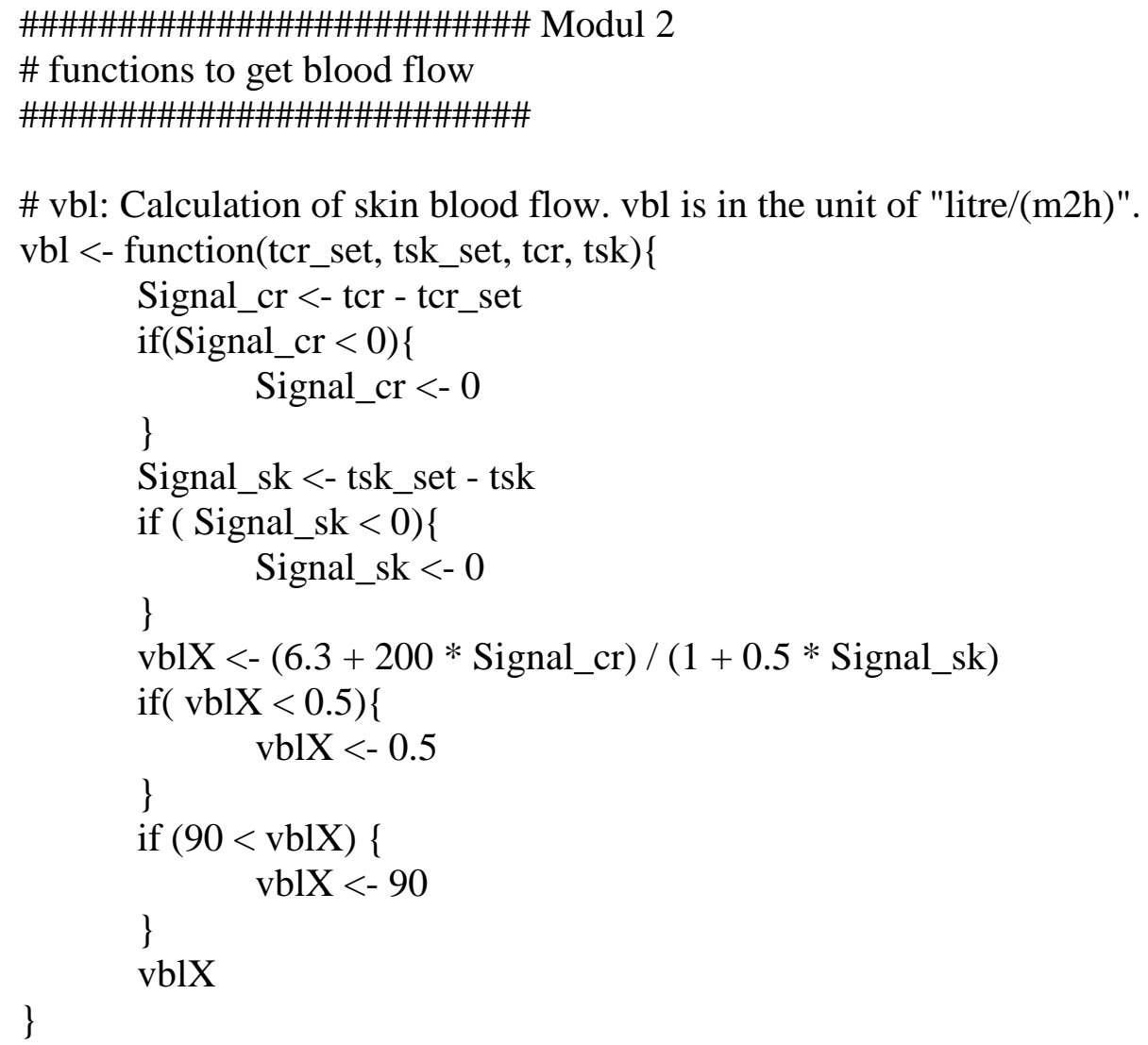

\# vbl Variation 2: \#Calculation of skin blood flow. vbl is in the unit of "litre/(m2h)".

vbl_cdil_str<- function(cdil, str1, tcr_set, tsk_set, tcr, tsk)\{ \# str1 changed from str due to being an $\mathrm{R}$ function

$$
\begin{aligned}
& \text { Signal_cr }<- \text { tcr }- \text { tcr_set } \\
& \text { if }(\text { Signal_cr }<0)\{
\end{aligned}
$$




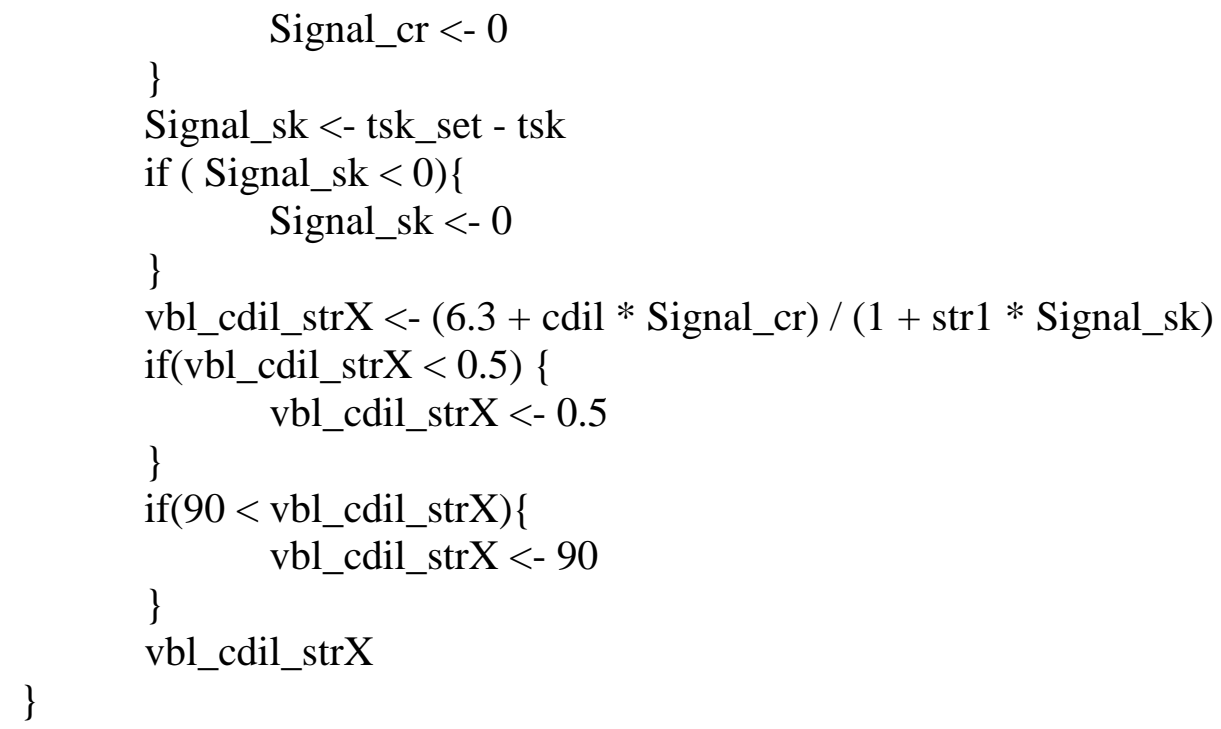

\#Calculation of convective heat transfer coefficient

\#Equations by Mitchell(1974) quoted from ASHRAE Handbook-Fundamentals-2005, p.8.8 hcv_m $<$ - function(v) \{ 


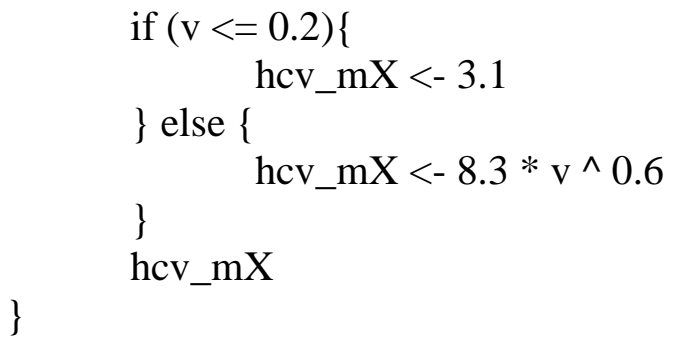

\#Calculation of convective heat transfer coefficient \#Equations used by Gagge et al.(1986)

\#Calculation of water vapor pressure in $\mathrm{Pa}$

p_vapor <- function(tCel, phi) $\{$ \# tCel original t

phi_air $<-$ phi $/ 100$

TK $<-$ tCel +273.15

p_vaporX <- phi_air * exp(25.89 - 5319 / TK)

\}

p_vaporX

\#\#\#\#\#\#\#\#\#\#\#\#\#\#

\# Modul 4

\# Calculation of Effective temperature 
fctET $<$ - function(top, ta, pha, w, im, pha_ET, im_star) \{

Delta $<-0.1$; $\operatorname{lr}<-16.5 * 10 \wedge(-3)$; TK0 <- 273.15

$\mathrm{C}<-$ top $+\mathrm{w} * \mathrm{im} * \operatorname{lr} * 0.01 *$ pha $* \exp (25.89-5319 /(\mathrm{TK} 0+\mathrm{ta}))$

tes $0<-$ ta

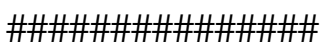

\# potential problem that loop is done once more than in Excel sheet

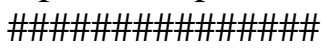

$\mathrm{Y}<-$ tes $0+\mathrm{w} *$ im_star $* \mathrm{lr} * 0.01 *$ pha_ET $* \exp (25.89-5319 /(\mathrm{TK} 0+$ tes0) $)-\mathrm{C}$

$\mathrm{Z}<-1+\mathrm{w} *$ im_star $* \operatorname{lr} * 0.01 *$ pha_ET $* \exp (25.89-5319 /(\mathrm{TK} 0+$ tes 0$)) * 5319 /$

$((\mathrm{TK} 0+\operatorname{tes} 0) \wedge 2)$

tes $1<-$ tes 0 - Y / Z

while (abs(tes1 - tes0) $>$ Delta $)\{$

tes0)) - C

$$
\mathrm{Y}<- \text { tes } 0+\mathrm{w} * \text { im_star } * \operatorname{lr} * 0.01 * \text { pha_ET * exp(25.89 - } 5319 /(\mathrm{TK} 0+
$$

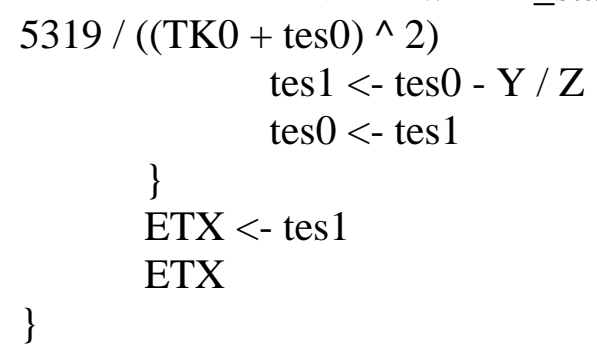

\# Calculation of thermal exergy contained by a body with heat capacity of "cp" WC_Ex <- function(cp, T1, TOO) \{

WC_ExX <- cp * ((T1 - TOO) - TOO * $\log (\mathrm{T} 1 / \mathrm{TOO}))$

WC_ExX

\}

\# Judgement of exergy regarding "warm" or "cool"

WC_X_check <- function(T1, TOO) \{

if $(\mathrm{T} 1<\mathrm{TOO})\{$

\} else \{

WC_X_checkX <- "cool"

WC_X_checkX <- "warm"

\}

WC_X_checkX

\}

\# Calculation of material(wet/dry) exergy contained by one cubic-meter of moist air WD_Ex <- function(T1, TOO, pv1, pvo $)\{$

POT $<-101325$

WD_ExX <- TOO / T1 * ((POT - pv1) * $\log ((\mathrm{POT}-\mathrm{pv} 1) /(\mathrm{POT}-\mathrm{pvo}))+\mathrm{pv} 1 *$ $\log (\mathrm{pv} 1 / \mathrm{pvo}))$ WD_ExX

\}

\# Calculation of material(wet/dry) exergy contained by one kilogram of liquid water

WD_Ex_lw <- function(TOO, pvso, pv1, pvo) \{

R_gas $<-8.314$ 


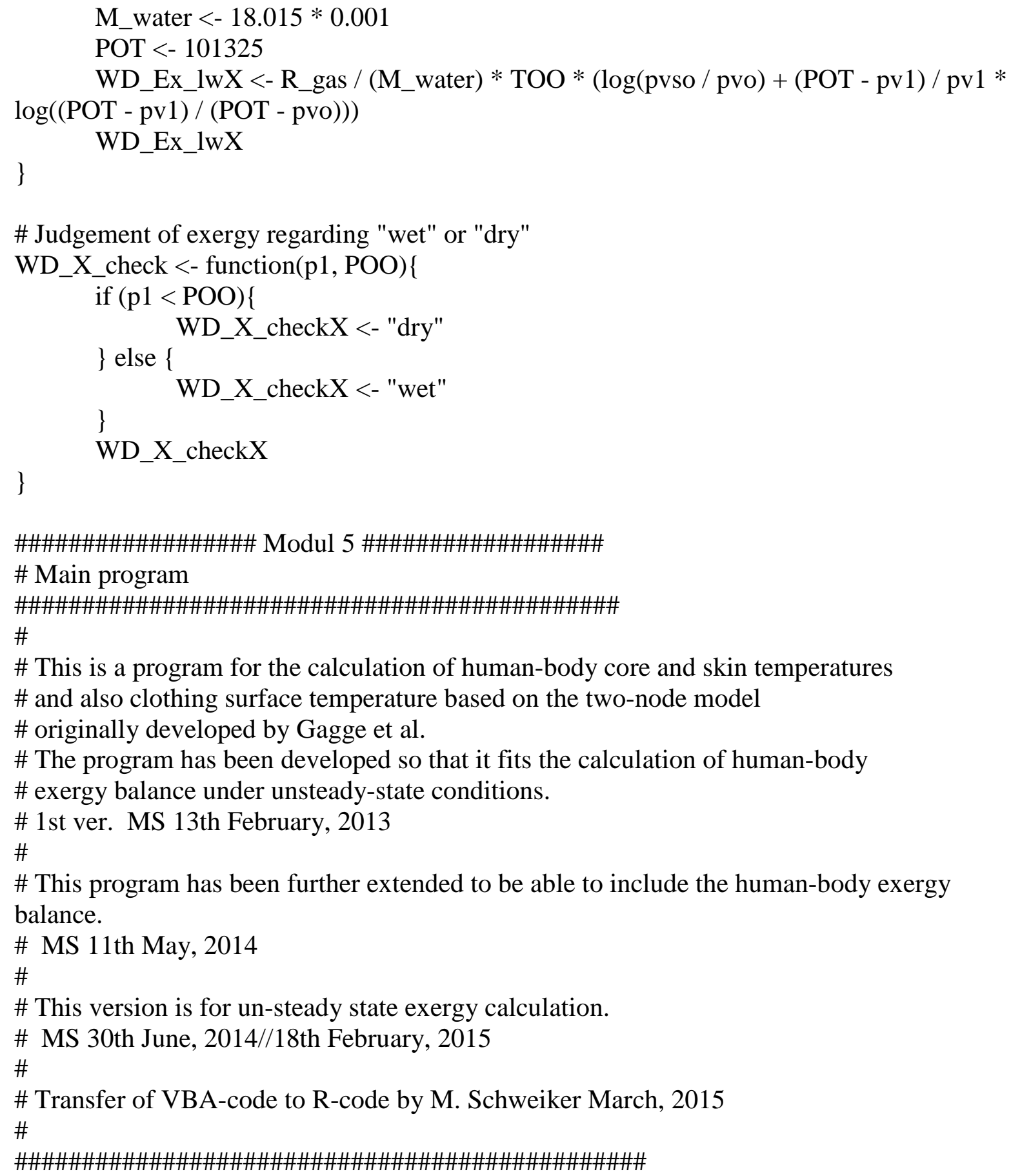




\section{\# Exergy output \\ XoutSTOREcoreu <- XoutSTOREshelu <- XoutAIRwcu <- XoutAIRwcwcu}

$<-$ XoutAIRwdu $<$ - XoutAIRwdwdu $<$ - XoutSWEATwcu $<$ - XoutSWEATwcwcu $<-$

XoutSWEATwdu <- XoutSWEATwdwdu <- XoutRADu <- XoutRADwcu <- XoutCONVu

$<-$ XoutCONVwcu $<$ - XoutTOTALu $<-$ NA

$$
\begin{aligned}
& \text { \# balance } \\
& \text { Xconsu <- TSKu <- TCRu <- NA }
\end{aligned}
$$

TK0 $<-273.15$

tsk_set $<-34$

tcr_set $<-37$

$\operatorname{lr}<-16.5 * 10 \wedge(-3)$

cdil $<-200$

sigma_tr $<-0.5 ;$ Csw $<-170$

M_air <- 28.97*0.001;

M_water $<-18.015 * 0.001$;

R_gas <- 8.314 \#[J/(molK)]

Row $<-1000 ;$ Roa $<-1.2 \#[\mathrm{~kg} / \mathrm{m} 3]$

Cp_body <- 3490; сра <- 1005; cpv <- 1846; cpw <- 4186 \#[J/(kgK)]

$\mathrm{PO}<-101325 \#[\mathrm{~N} / \mathrm{m} 2<-\mathrm{J} / \mathrm{m} 3]$

\# radiation area of human body - taking account for covered parts by other parts of body (e.g. inner parts of arm) - coefficients taken from Fanger

\# Abody <- $0.008883 *$ Hbody $\wedge 0.663 *$ Mbody $\wedge 0.444$

r_MA <- Mbody / Abody

colIcl <- dfData\$CLI \# Clothing insulation [clo]

colva $<-$ dfData\$XVA \# Indoor air velocity $[\mathrm{m} / \mathrm{s}]$

colMet $<$ - dfData \$XMM \# Metabolic rate [met]

coltmr $<$ - dfData\$XTir \# mean radiant temp $\left[{ }^{\circ} \mathrm{C}\right]$

colta $<$ - dfData\$XTia \# air temp $\left[{ }^{\circ} \mathrm{C}\right]$

colphia <- dfData\$XRHi \# relative humidity indoors [\%]

colto_env $<$ - dfData\$XTout \# outdoor temp $\left[{ }^{\circ} \mathrm{C}\right]$

colphia_env <- dfData\$XRHo \# relative humidity outdoors [\%]

\#

jcount $<-0$;

\#

\# A series of calculation timestep by timestep

\# adjust here for input of individual conditions in each line

\#

\#

runs $<-$ nrow(dfData)

$\mathrm{i}<-1$

Icl $<-$ colIcl[i] \# Clothing insulation [clo]

va $<-$ colva[i] \# Indoor air velocity [m/s] 
Met <- colMet[i] \# Metabolic rate [met]

tmr $<$ - coltmr[i] \# mean radiant temp $\left[{ }^{\circ} \mathrm{C}\right]$

ta $<-$ colta[i] \# air temp $\left[{ }^{\circ} \mathrm{C}\right]$

phia $<$ - colphia[i] \# relative humidity indoors [\%]

to_env $<$ - colto_env[i] \# outdoor temp $\left[{ }^{\circ} \mathrm{C}\right]$

phia_env <- colphia_env[i] \# relative humidity outdoors [\%]

\# warm-up period (here 30 minutes) - see also discussion in paper

for $(\mathrm{j}$ in $1: 30)\{$

\# extract single value from time series data

Dt_cal $<-60$

qmet $<$ - Meta_therm(Met, basMet)

fcl $<-1+0.15 *$ Icl

Rcl $<-0.155 *$ Icl

TKa $<-$ ta + TK0; TKmr $<-$ tmr + TK0

TKo_env <- to_env + TK0

Shukuya p. 268

pv_env <- p_vapor(to_env, phia_env) \#--------Module_1 function see Book

hr $<-6.13 *$ frad * eps \# radiative heat transfer coefficient

hc <- hcv_g(va, Met, basMet) \# convective heat transfer coefficient \#---------

Module_1

top $<-(\mathrm{hr} * \mathrm{tmr}+\mathrm{hc} * \mathrm{ta}) /(\mathrm{hr}+\mathrm{hc})$

FFCL $<-1 /(1+0.155 *$ Icl * fcl * (hr + hc) $)$;

FPCL $<-1 /(1+0.155 *$ Icl * fcl * hc / i_c $)$ \# related to evaporation

$\mathrm{CL}<-1 /(1+0.155 *$ Icl * fcl * hc / i_c $)$

$\mathrm{im}<-$ hc $*$ FPCL / ((hr + hc) $*$ FFCL $)$

Icl_star $<-0.6$; fcl_star $<-1+0.15 *$ Icl_star

hc_star $<-$ hcv_g( $0.1,1$, basMet $)$

FFCL_star <- $1 /(1+0.155 *$ Icl_star * fcl_star * $(\mathrm{hr}+$ hc_star $))$

FPCL_star $<-1 /(1+0.155 *$ Icl_star * fcl_star * hc_star / i_c $)$

im_star <- hc_star * FPCL_star / ( $(\mathrm{hr}+\mathrm{hc}$ _star $) *$ FFCL_star $)$;

C_res <- $0.0014 *$ (basMet * Met) * (34 - ta) \# heat transfer to environment by

convection in relation to respiration (empirical equation by Fanger)

pva <- p_vapor(ta, phia)\#--------Module_1

E_res <- $0.0173 *$ (basMet * Met) * (5.87 - pva / 1000) \# heat removed by

evaporation in relation to respiration (empirical equation by Fanger)

\#Else

q_shiv <- Mshiv(tcr_set, tsk_set, tcr, tsk)\#--------Module_3

Vbl_s <- vbl_cdil_str(cdil, sigma_tr, tcr_set, tsk_set, tcr, tsk)\# blood flow rate \#--------Module_2

\# next line is core of Gagge model. If blood flow becomes lower, than skin layer gets more dominant 
dominance

alfa_sk <- $0.0418+0.745$ / (Vbl_s + 0.585); \# factor to adjust for difference in

K_s $<-5.28+1.163 *$ Vbl_s \# conductance between core and skin layer

Qcr <- $(1$ - alfa_sk $) *$ r_MA * Cp_body; Qsk <- alfa_sk * r_MA * Cp_body \# heat capacity of core and skin layer

tcr_n <- $(1$ - Dt_cal * K_s / Qcr) * tcr + Dt_cal / Qcr * (qmet + q_shiv - (C_res + E_res $)+\mathrm{K} \_s *$ tsk) \# core temperature at time step before step calculated

psks <- p_vapor(tsk, 100)\# saturated water vapour pressure at skin surface calculated with pure water , i.e. adaptive processes such as less salt in sweat might be put heresee also p. 281 of book Shukuya \#--------Module_1

Emax <- FPCL * $(\mathrm{fcl} * \mathrm{lr} * \mathrm{hc}) *(\mathrm{psks}-\mathrm{pva}) \#$ max rate of water dispersion when the whole skin surface is wet

tb <- alfa_sk * tsk + (1 - alfa_sk) * tcr; \# average body temperature using calculated Tsk and Tcr

tb_set <- alfa_sk * tsk + $(1$ - alfa_sk $) *$ tcr_set \# average body temperature using set-point values for Tsk and Tcr

Ersw <- Csw * (tb - tb_set) * exp((tsk - tsk_set) / 10.7) \# amount of sweat

secretion

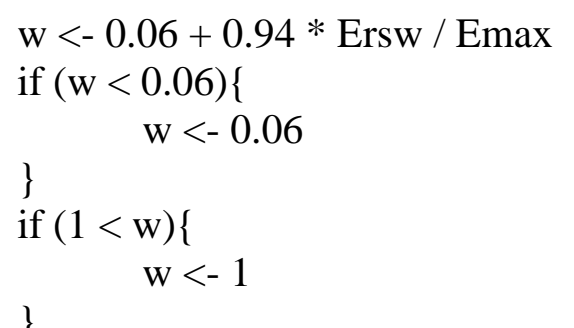

DTQ <- Dt_cal / Qsk

tsk_n <- $\left(1-\mathrm{DTQ} * \mathrm{~K} \_\mathrm{s}-\mathrm{DTQ} * \mathrm{fcl} *\right.$ FFCL $\left.*(\mathrm{hr}+\mathrm{hc})\right) *$ tsk $-\mathrm{DTQ} * \mathrm{w} *$

$\mathrm{fcl} * \mathrm{lr} * \mathrm{hc} * \mathrm{FPCL} * \mathrm{psks}+\mathrm{DTQ} *\left(\mathrm{~K} \_\mathrm{s} * \mathrm{tcr}+\mathrm{fcl} *(\mathrm{hr}+\mathrm{hc}) * \mathrm{FFCL} *\right.$ top $+\mathrm{w} * \mathrm{fcl} * \operatorname{lr} *$ hc * FPCL * pva) \# tsk in next step

fcl * hc)

tcl_n $<-\left((1 / \mathrm{Rcl}) * \mathrm{tsk} \_\mathrm{n}+\mathrm{fcl} * \mathrm{hr} * \mathrm{tmr}+\mathrm{fcl} * \mathrm{hc} * \mathrm{ta}\right) /(1 / \mathrm{Rcl}+\mathrm{fcl} * \mathrm{hr}+$

\#

\# Exergy balance

\#

\# Thermal exergy generation by metabolism

\#

TKcr_n $<-$ tcr_n + TK0; TKsk_n $<-$ tsk_n + TK0; TKcl_n $<-$ tcl_n + TK0

Meta_energy $<-$ qmet + q_shiv

X_met <- Meta_energy * (1 - TKo_env / TKcr_n);

X_metwc $<-$ WC_X_check(TKcr_n, TKo_env)

\# Inhaled humid air

Vin $<-1.2 * 10 \wedge(-6) *$ Meta_energy \# Volume of air intake [V/s]

* TKa)) * pva

cpav <- cpa * (M_air / (R_gas * TKa $) *(\mathrm{PO}-\mathrm{pva})+\mathrm{cpv} *\left(\mathrm{M} \_\right.$water / (R_gas

X_inhale_wc <- Vin * WC_Ex(cpav, TKa, TKo_env); 
X_inhale_wcwc <- WC_X_check(TKa, TKo_env)\#--------Module_4

X_inhale_wd <- Vin * WD_Ex(TKa, TKo_env, pva, pv_env);

X_inhale_wdwd <- WD_X_check(pva, pv_env)\#--------Module_4

exhaled air

\# Liquid water generated in the core by metabolism to be dispersed into the

Vw_core $<-$ Vin $*(0.029-0.049 * 10 \wedge(-4) *$ pva $)$

X_lw_core_wc $<-$ Vw_core * Roa * WC_Ex(cpw, TKcr_n, TKo_env);

X_lw_core_wcwc <- WC_X_check(TKcr_n, TKo_env) \#--------Module_4

pvs_env <- p_vapor(to_env, 100)

X_lw_core_wet $<-$ Vw_core * Roa * R_gas / M_water * TKo_env * log(pvs_env / pv_env)

X_lw_core_wetwd <- "wet"

\# Liquid water generated in the shell by metabolism to be secreted as sweat

Vw_shell_row $<-\mathrm{w}^{*}$ Emax / $(2450 * 1000)$

X_lw_shell_wc $<-$ Vw_shell_row *WC_Ex(cpw, TKsk_n, TKo_env);

X_lw_shell_wcwc $<-$ WC_X_check(TKsk_n, TKo_env)\#--------Module_4

pv_env);

X_lw_shell_wd <- Vw_shell_row *WD_Ex_lw(TKo_env, pvs_env, pva,

X_lw_shell_wdwd <- WD_X_check(pva, pv_env) \#--------Module_4

\# Radiant exergy input

X_in_rad <-fcl * hr * (TKmr - TKo_env $) \wedge 2$ / (TKmr + TKo_env);

X_in_radwc $<-$ WC_X_check(TKmr, TKo_env)

\# Total exergy input

Xin_total $<-X \_m e t+X \_$inhale_wc + X_inhale_wd + X_lw_core_wc + X_lw_core_wet + X_lw_shell_wc + X_lw_shell_wd + X_in_rad

\# Exergy stored

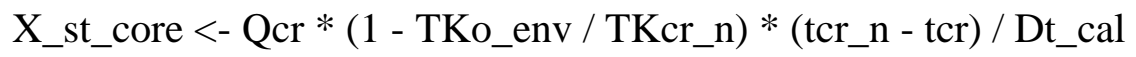

X_st_shell <- Qsk * $(1$ - TKo_env / TKsk_n) * (tsk_n - tsk) / Dt_cal

\# Exhaled humid air

pvss_cr <- p_vapor(tcr_n, 100)

cpav <- cpa * (M_air / (R_gas * TKcr_n $)) *(\mathrm{PO}-$ pvss_cr $)+$ cpv * (M_water /

$\left(\mathrm{R} \_\right.$gas $*$ TKcr_n $\left.)\right) *$ pvss_cr

X_exhale_wc <- Vin * WC_Ex(cpav, TKcr_n, TKo_env);

X_exhale_wcwc <- WC_X_check(TKcr_n, TKo_env) \#--------Module_4 
X_exhale_wd <- Vin *WD_Ex(TKcr_n, TKo_env, pvss_cr, pv_env); X_exhale_wdwd <- WD_X_check(pvss_cr, pv_env)\#--------Module_4

evaporated sweat

\# Water vapor originating from the sweat and humid air containing the

X_sweat_wc <- Vw_shell_row * WC_Ex(cpv, TKcl_n, TKo_env);

X_sweat_wcwc <- WC_X_check(TKcl_n, TKo_env)\#--------Module_4

X_sweat_wd <- Vw_shell_row* WD_Ex_lw(TKo_env, pva, pva, pv_env);

X_sweat_wdwd <- WD_X_check(pva, pv_env) \#--------Module_4

\# Radiant exergy output

X_out_rad $<-\mathrm{fcl} * \mathrm{hr} *\left(\mathrm{TKcl} \_\mathrm{n}-\mathrm{TKo} \_\right.$env $) \wedge 2$ / (TKcl_n + TKo_env);

X_out_radwc $<-$ WC_X_check(TKcl_n, TKo_env)

\# Exergy transfer by convection

X_out_conv <- fcl * hc * (TKcl_n - TKa) * (1. - TKo_env / TKcl_n);

X_out_convwc $<-$ WC_X_check(TKcl_n, TKo_env)

Xout_total $<-$ X_st_core + X_st_shell + X_exhale_wc + X_exhale_wd + X_sweat_wc + X_sweat_wd + X_out_rad + X_out_conv

X_consumption $<<-$ Xin_total - Xout_total

ET_star <<- fctET(top, ta, phia, w, im, 50, im); \#--------Module_4

tcr $<-$ tcr_n

tsk $<-$ tsk_n

\}

jcount $<-$ jcount +1 ;

\# Output values

\# Exergy input

XinMETu[i] <- X_met \#metabolism

XinMETwcu[i] <- X_metwc \#metabolism warm/cold

XinAIRwcu[i] <- X_inhale_wc \# inhaled humid air

XinAIRwcwcu[i] <- X_inhale_wcwc

XinAIRwdu[i] <- X_inhale_wd \#

XinAIRwdwdu[i] <- X_inhale_wdwd \# wet/dry

XinLUNGwcu[i] <- X_lw_core_wc \# water lung

XinLUNGwcwcu[i] <- X_lw_core_wcwc

XinLUNGwdu[i] <- X_lw_core_wet

XinLUNGwdwdu[i] <- X_lw_core_wetwd

XinSHELLwcu[i] <- X_lw_shell_wc \# water sweat

XinSHELLwcwcu[i] <- X_lw_shell_wcwc 
XinSHELLwdu[i] <- X_lw_shell_wd

XinSHELLwdwdu[i] <- X_lw_shell_wdwd

XinRADu[i] <- X_in_rad \# radiation in

XinRADwcu[i] <- X_in_radwc

XinTOTALu[i] <- Xin_total \# TOTAL exergy input

\# Exergy output

XoutSTOREcoreu[i] <- X_st_core \# exergy stored

XoutSTOREshelu[i] <- X_st_shell

XoutAIRwcu[i] <- X_exhale_wc \# exhaled humid air

XoutAIRwcwcu[i] <- X_exhale_wcwc

XoutAIRwdu[i] <- X_exhale_wd

XoutAIRwdwdu[i] <- X_exhale_wdwd

XoutSWEATwcu[i] <- X_sweat_wc \# water vapour

XoutSWEATwcwcu[i] <- X_sweat_wcwc

XoutSWEATwdu[i] <- X_sweat_wd

XoutSWEATwdwdu[i] <- X_sweat_wdwd

XoutRADu[i] <- X_out_rad \# radiation out

XoutRADwcu[i] <- X_out_radwc

XoutCONVu[i] <- X_out_conv \# convection

XoutCONVwcu[i] <- X_out_convwc

XoutTOTALu[i] <- Xout_total \# TOTAL exergy out

\# balance

Xconsu[i] <- X_consumption \# exergy consumption total

$\mathrm{TSKu}[\mathrm{i}]<-$ tsk

TCRu[i] $<-$ tcr

\# from here start dynamic series of data from row 2 of dataset for (i in 2:runs) \{

\# Calc Dtcal dependend on timediff between rows + approx if more than 1 minute time difference

Dt_cal <- as.numeric(difftime(dfData\$DateTime[i], dfData\$DateTime[i-1], units="secs")) \# in seconds

if(Dt_cal > 60) $\{$ \# if time difference is greater than 1 minute (leading to the calcs getting unstable), intermediate values or calculated

between interval

nRunsInter $<<$ - trunc(Dt_cal/60-1,0) \# calc number of minutes in

Dt_cal <- Dt_cal / (nRunsInter+1)

for ( $\mathrm{k}$ in 1: nRunsInter) \{

\# get linear approximated values for intermediate times

Clothing insulation [clo]

Icl <- colIcl[i-1] + $\mathrm{k}^{*}((\operatorname{colIcl}[\mathrm{i}]-\operatorname{colIcl}[\mathrm{i}-1]) /($ nRunsInter+1) $) \#$

va $<-$ colva[i-1] + k*((colva[i] - colva[i-1])/(nRunsInter+1) $\#$

Indoor air velocity $[\mathrm{m} / \mathrm{s}]$ 
1])/(nRunsInter+1)) \# Metabolic rate [met]

$$
\text { Met }<-\operatorname{colMet}[\mathrm{i}-1]+\mathrm{k}^{*}((\operatorname{colMet}[\mathrm{i}]-\operatorname{colMet}[\mathrm{i}-
$$

tmr $<-$ coltmr $[\mathrm{i}-1]+\mathrm{k} *((\operatorname{coltmr}[\mathrm{i}]-\operatorname{coltmr}[\mathrm{i}-$

1])/(nRunsInter+1)) \# mean radiant temp $\left[{ }^{\circ} \mathrm{C}\right]$

temp $\left[{ }^{\circ} \mathrm{C}\right]$

ta $<-$ colta[i-1] $+\mathrm{k}^{*}((\operatorname{colta}[\mathrm{i}]-\operatorname{colta}[\mathrm{i}-1]) /($ nRunsInter +1$))$ \# air

phia <- colphia[i-1] + k*((colphia[i] - colphia[i-

1])/(nRunsInter+1)) \# relative humidity indoors [\%]

to_env <- colto_env[i-1] + k*((colto_env[i] - colto_env[i-

1])/(nRunsInter+1)) \# outdoor temp $\left[{ }^{\circ} \mathrm{C}\right]$

phia_env <- colphia_env[i-1] + k*((colphia_env[i] -

colphia_env[i-1])/(nRunsInter+1)) \# relative humidity outdoors [\%]

$$
\begin{aligned}
& \text { qmet <- Meta_therm(Met, basMet) } \\
& \text { fcl }<-1+0.15 * \text { Icl } \\
& \text { Rcl }<-0.155 * \text { Icl } \\
& \text { TKa <- ta + TK0; TKmr <- tmr + TK0 } \\
& \text { TKo_env <- to_env + TK0 } \\
& \text { pv_env <- p_vapor(to_env, phia_env) \#--------Module_1 }
\end{aligned}
$$

function see Book Shukuya p. 268

$$
\begin{aligned}
& \text { hr }<-6.13 * \text { frad * eps \# radiative heat transfer coefficient } \\
& \text { hc }<- \text { hcv_g(va, Met, basMet) \# convective heat transfer }
\end{aligned}
$$

coefficient \#---------Module_1

$$
\begin{aligned}
& \text { top }<-(\mathrm{hr} * \mathrm{tmr}+\mathrm{hc} * \mathrm{ta}) /(\mathrm{hr}+\mathrm{hc}) \\
& \text { FFCL }<-1 /(1+0.155 * \text { Icl * fcl * (hr }+ \text { hc })) \text {; } \\
& \text { FPCL }<-1 /(1+0.155 * \text { Icl } * \text { fcl * hc / i_c }) \\
& \text { CL }<-1 /(1+0.155 * \text { Icl * fcl * hc / i_c }) \\
& \mathrm{im}<- \text { hc } * \text { FPCL } /((\mathrm{hr}+\mathrm{hc}) * \text { FFCL }) \\
& \text { Icl_star }<-0.6 \text {; fcl_star }<-1+0.15 * \text { Icl_star } \\
& \text { hc_star }<- \text { hcv_g}(0.1,1 \text {, basMet }) \\
& \text { FFCL_star }<-1 /(1+0.155 * \text { Icl_star * fcl_star * }(\mathrm{hr}+
\end{aligned}
$$

hc_star))

FPCL_star <- 1 / $(1+0.155 *$ Icl_star * fcl_star * hc_star / i_c $)$ im_star <- hc_star * FPCL_star / ((hr + hc_star) * FFCL_star);

C_res <- $0.0014 *$ (basMet * Met) * (34 - ta) \# heat transfer to environment by convection in relation to respiration (empirical equation by Fanger)

$$
\begin{aligned}
& \text { pva }<- \text { p_vapor(ta, phia)\#--------Module_1 } \\
& \text { E_res <- } 0.0173 * \text { (basMet * Met) } *(5.87 \text { - pva / 1000) \# heat }
\end{aligned}
$$
removed by evaporation in relation to respiration (empirical equation by Fanger)

\#Else

q_shiv <- Mshiv(tcr_set, tsk_set, tcr, tsk)\#--------Module_3

Vbl_s <- vbl_cdil_str(cdil, sigma_tr, tcr_set, tsk_set, tcr, tsk)\# blood flow rate \#--------Module_2 
\# next line is core of Gagge model. If blood flow becomes lower, than skin layer gets more dominant

for difference in dominance

$$
\text { alfa_sk <- } 0.0418+0.745 \text { / (Vbl_s + 0.585); \# factor to adjust }
$$

skin layer

$\mathrm{K} \_\mathrm{s}<-5.28+1.163 *$ Vbl_s \# conductance between core and

Qcr <- (1 - alfa_sk)*r_MA * Cp_body; Qsk <- alfa_sk * r_MA

* Cp_body \# heat capacity of core and skin layer

tcr_n $<-\left(1-\mathrm{Dt} \_\right.$cal $*$ K_s / Qcr) $*$ tcr + Dt_cal / Qcr * (qmet + q_shiv - (C_res + E_res) + K_s * tsk) \# core temperature at time step before step calculated psks <- p_vapor(tsk, 100)\# saturated water vapour pressure at skin surface calculated with pure water, i.e. adaptive processes such as less salt in sweat might be put heresee also p. 281 of book Shukuya \#--------Module_1

Emax <- FPCL * (fcl * lr * hc)* (psks - pva) \# max rate of water dispersion when the whole skin surface is wet temperature using calculated Tsk and Tcr

tb $<$ - alfa_sk * tsk + $(1$ - alfa_sk $) *$ tcr; \# average body

$$
\text { tb_set <- alfa_sk * tsk + (1 - alfa_sk }) * \text { tcr_set \# average body }
$$

temperature using set-point values for Tsk and Tcr

$$
\text { Ersw <- Csw * (tb - tb_set) * } \exp ((\text { tsk - tsk_set }) / 10.7) \#
$$

amount of sweat secretion

$$
\begin{aligned}
& \mathrm{w}<-0.06+0.94 * \text { Ersw / Emax } \\
& \text { if }(\mathrm{w}<0.06)\{ \\
& \quad \mathrm{w}<-0.06 \\
& \begin{array}{l}
\text { if }(1<\mathrm{w})\{ \\
\mathrm{w}<-1
\end{array} \\
& \text { \} }
\end{aligned}
$$

$$
\begin{aligned}
& \text { DTQ }<- \text { Dt_cal / Qsk } \\
& \text { tsk_n }<-\left(1-\mathrm{DTQ} * \mathrm{~K} \_\mathrm{s}-\mathrm{DTQ} * \mathrm{fcl} * \mathrm{FFCL} *(\mathrm{hr}+\mathrm{hc})\right) * \mathrm{tsk} \\
& -\mathrm{DTQ} * \mathrm{w} * \mathrm{fcl} * \mathrm{lr} * \mathrm{hc} * \mathrm{FPCL} * \mathrm{psks}+\mathrm{DTQ} *\left(\mathrm{~K} \_\mathrm{s} * \mathrm{tcr}+\mathrm{fcl} *(\mathrm{hr}+\mathrm{hc}) * \mathrm{FFCL} * \mathrm{top}+\right. \\
& \mathrm{w} * \mathrm{fcl} * \mathrm{lr} * \mathrm{hc} * \mathrm{FPCL} * \text { pva) } \# \mathrm{tsk} \text { in next step } \\
& \mathrm{tcl} \mathrm{n}<-\left((1 / \mathrm{Rcl}) * \mathrm{tsk} \_\mathrm{n}+\mathrm{fcl} * \mathrm{hr} * \mathrm{tmr}+\mathrm{fcl} * \mathrm{hc} * \mathrm{ta}\right) /(1 / \\
& \mathrm{Rcl}+\mathrm{fcl} * \mathrm{hr}+\mathrm{fcl} * \mathrm{hc})
\end{aligned}
$$

Module_4

$$
\text { ET_star }<<- \text { fctET(top, ta, phia, w, im, 50, im); \#-------- }
$$

$$
\begin{aligned}
& \text { tcr }<- \text { tcr_n } \\
& \text { tsk }<- \text { tsk_n }
\end{aligned}
$$

\} \# end for $\mathrm{k}$ times in between interval

\} \# end if Dtcal $>60$

\# extract single value from time series data

Icl <- colIcl[i] \# Clothing insulation [clo] 


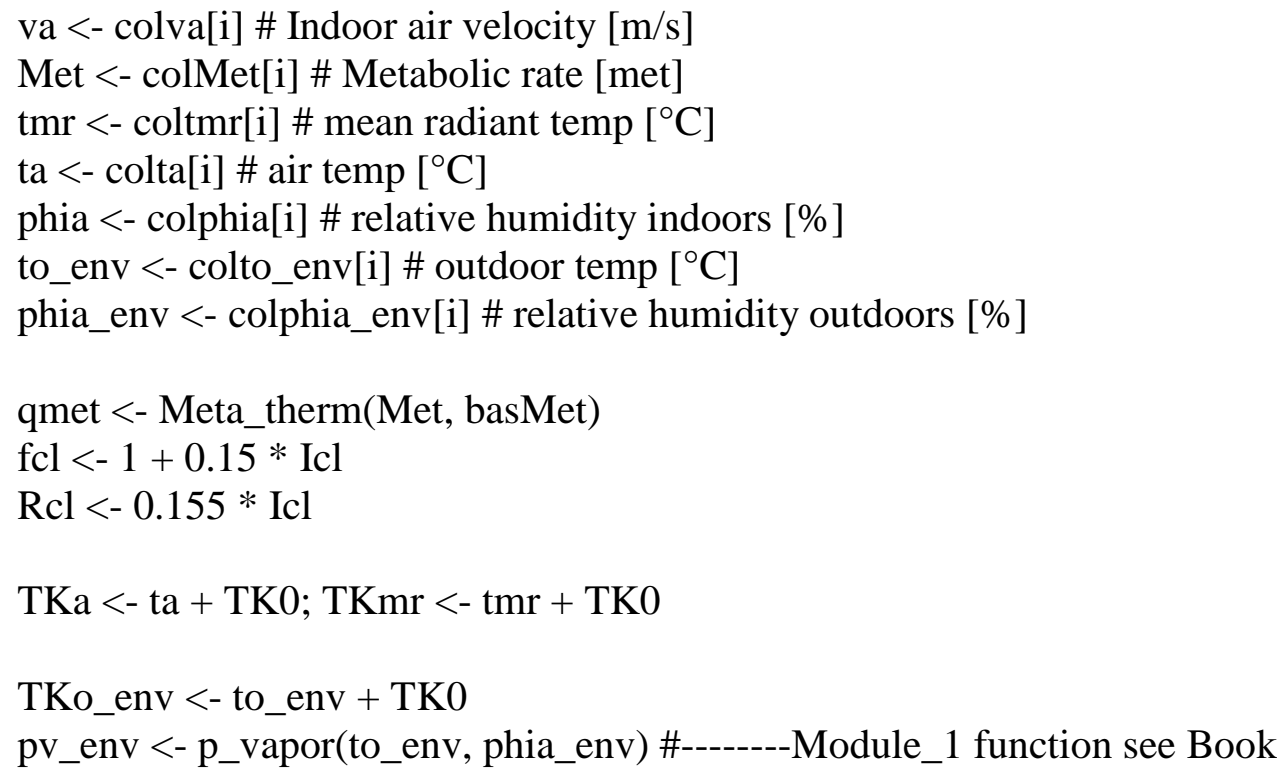

Shukuya p. 268

hr $<-6.13 *$ frad * eps \# radiative heat transfer coefficient

Module_1

hc <- hcv_g(va, Met, basMet) \# convective heat transfer coefficient \#---------

top $<-(\mathrm{hr} * \mathrm{tmr}+\mathrm{hc} * \mathrm{ta}) /(\mathrm{hr}+\mathrm{hc})$

FFCL $<-1 /(1+0.155 *$ Icl * fcl * (hr + hc) $)$;

FPCL $<-1 /(1+0.155 *$ Icl $*$ fcl $*$ hc $/$ i_c $)$ \# related to evaporation

CL $<-1 /(1+0.155 *$ Icl $*$ fcl $*$ hc $/$ i_c $)$

$\mathrm{im}<-$ hc $*$ FPCL / ((hr + hc) $*$ FFCL $)$

Icl_star $<-0.6$; fcl_star $<-1+0.15 *$ Icl_star

hc_star $<-$ hcv_g $(0.1,1$, basMet $)$

FFCL_star <- $1 /(1+0.155 *$ Icl_star * fcl_star * (hr + hc_star $))$

FPCL_star <- $1 /(1+0.155 *$ Icl_star * fcl_star * hc_star / i_c $)$

im_star <- hc_star * FPCL_star / ((hr + hc_star $) *$ FFCL_star $)$;

C_res <- $0.0014 *$ (basMet * Met)* (34 - ta) \# heat transfer to environment by

convection in relation to respiration (empirical equation by Fanger)

pva <- p_vapor(ta, phia)\#---------Module_1

E_res $<-0.0173 *$ (basMet * Met) * $(5.87$ - pva / 1000) \# heat removed by

evaporation in relation to respiration (empirical equation by Fanger)

\#Else

q_shiv <- Mshiv(tcr_set, tsk_set, tcr, tsk)\#--------Module_3

Vbl_s <- vbl_cdil_str(cdil, sigma_tr, tcr_set, tsk_set, tcr, tsk)\# blood flow rate \#--------Module_2

\# next line is core of Gagge model. If blood flow becomes lower, than skin layer gets more dominant

alfa_sk <- $0.0418+0.745$ / (Vbl_s + 0.585); \# factor to adjust for difference in

dominance

K_s $<-5.28+1.163 *$ Vbl_s \# conductance between core and skin layer 
Qcr <- $(1$ - alfa_sk $) *$ r_MA * Cp_body; Qsk <- alfa_sk * r_MA *Cp_body \# heat capacity of core and skin layer

tcr_n <- (1 - Dt_cal * K_s / Qcr) * tcr + Dt_cal / Qcr * (qmet + q_shiv - (C_res + E_res) + K_s * tsk) \# core temperature at time step before step calculated

psks <- p_vapor(tsk, 100)\# saturated water vapour pressure at skin surface calculated with pure water, i.e. adaptive processes such as less salt in sweat might be put heresee also p. 281 of book Shukuya \#--------Module_1

Emax <- FPCL * $(\mathrm{fcl} * \mathrm{lr} * \mathrm{hc}) *(\mathrm{psks}-\mathrm{pva}) \#$ max rate of water dispersion when the whole skin surface is wet

tb <- alfa_sk * tsk + (1 - alfa_sk) * tcr; \# average body temperature using calculated Tsk and Tcr

tb_set <- alfa_sk * tsk $+(1$ - alfa_sk $) *$ tcr_set \# average body temperature using set-point values for Tsk and Tcr

secretion

$$
\text { Ersw <- Csw * (tb - tb_set) * exp((tsk - tsk_set) / 10.7) \# amount of sweat }
$$

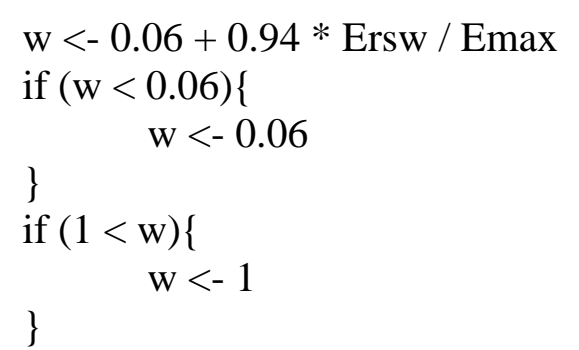

$$
\begin{aligned}
& \mathrm{DTQ}<- \text { Dt_cal } / \text { Qsk } \\
& \text { tsk_n }<-\left(1-\mathrm{DTQ} * \mathrm{~K} \_\mathrm{s}-\mathrm{DTQ} * \mathrm{fcl} * \mathrm{FFCL} *(\mathrm{hr}+\mathrm{hc})\right) * \mathrm{tsk}-\mathrm{DTQ} * \mathrm{w} *
\end{aligned}
$$

$\mathrm{fcl} * \mathrm{lr} * \mathrm{hc} * \mathrm{FPCL} * \mathrm{psks}+\mathrm{DTQ} *\left(\mathrm{~K} \_\mathrm{s} * \mathrm{tcr}+\mathrm{fcl} *(\mathrm{hr}+\mathrm{hc}) *\right.$ FFCL $*$ top $+\mathrm{w} * \mathrm{fcl} * \operatorname{lr} *$ hc * FPCL * pva) \# tsk in next step

fcl * hc)

tcl_n $<-\left((1 / \mathrm{Rcl}) * \mathrm{tsk} \_\mathrm{n}+\mathrm{fcl} * \mathrm{hr} * \mathrm{tmr}+\mathrm{fcl} * \mathrm{hc} * \mathrm{ta}\right) /(1 / \mathrm{Rcl}+\mathrm{fcl} * \mathrm{hr}+$

\#

\# Exergy balance

\#

\# Thermal exergy generation by metabolism

\#

TKcr_n $<-$ tcr_n + TK0; TKsk_n $<-$ tsk_n + TK0; TKcl_n $<-$ tcl_n + TK0

Meta_energy $<-$ qmet + q_shiv

X_met <- Meta_energy * (1 - TKo_env / TKcr_n);

xwc <- WC_X_check(TKcr_n, TKo_env)

\# Inhaled humid air

Vin $<-1.2 * 10 \wedge(-6) *$ Meta_energy \# Volume of air intake [V/s]

* TKa)) * pva

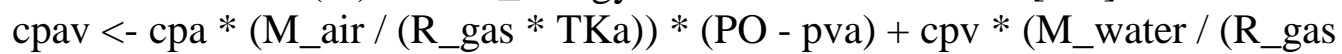

X_inhale_wc $<-$ Vin * WC_Ex(cpav, TKa, TKo_env); xwc $<-$

WC_X_check(TKa, TKo_env)\#--------Module_4 
X_inhale_wd <- Vin * WD_Ex(TKa, TKo_env, pva, pv_env); xwd <WD_X_check(pva, pv_env)\#--------Module_4

exhaled air

\# Liquid water generated in the core by metabolism to be dispersed into the

Vw_core $<$ - Vin $*(0.029-0.049 * 10 \wedge(-4) *$ pva $)$

X_lw_core_wc $<-$ Vw_core * Roa * WC_Ex(cpw, TKcr_n, TKo_env); xwc <WC_X_check(TKcr_n, TKo_env) \#--------Module_4

pvs_env $<$ - p_vapor(to_env, 100)

X_lw_core_wet $<-$ Vw_core $*$ Roa $*$ R_gas / M_water * TKo_env *

log(pvs_env / pv_env)

\# Liquid water generated in the shell by metabolism to be secreted as sweat

Vw_shell_row $<-\mathrm{w} *$ Emax / $(2450 * 1000)$

X_lw_shell_wc <- Vw_shell_row * WC_Ex(cpw, TKsk_n, TKo_env); xwc <WC_X_check(TKsk_n, TKo_env)\#--------Module_4

X_lw_shell_wd <- Vw_shell_row * WD_Ex_lw(TKo_env, pvs_env, pva, pv_env); xwd <- WD_X_check(pva, pv_env) \#--------Module_4

\# Radiant exergy input

X_in_rad <- fcl * hr * (TKmr - TKo_env) $\wedge 2$ / (TKmr + TKo_env); xwc <WC_X_check(TKmr, TKo_env)

\# Total exergy input

Xin_total <- X_met + X_inhale_wc + X_inhale_wd + X_lw_core_wc + X_lw_core_wet $+\bar{X}$ _llw_shell_wc + X_lw_shell_wd + X_in_rad

\# Exergy stored

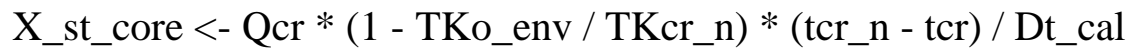

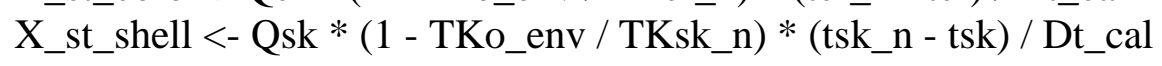

\# Exhaled humid air

pvss_cr $<-$ p_vapor(tcr_n, 100)

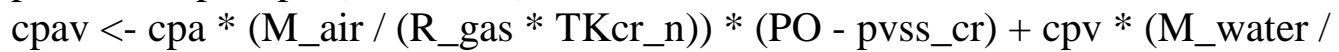

(R_gas * TKcr_n) $) *$ pvss_cr

X_exhale_wc <- Vin *WC_Ex(cpav, TKcr_n, TKo_env); xwc <-

WC_X_check(TKcr_n, TKo_env) \#--------Module_4

X_exhale_wd <- Vin *WD_Ex(TKcr_n, TKo_env, pvss_cr, pv_env); xwd <WD_X_check(pvss_cr, pv_env)\#--------Module_4 
evaporated sweat

\# Water vapor originating from the sweat and humid air containing the

X_sweat_wc $<-$ Vw_shell_row $*$ WC_Ex(cpv, TKcl_n, TKo_env); xwc $<-$ WC_X_check(TKcl_n, TKo_env)\#--------Module_4

X_sweat_wd <- Vw_shell_row* WD_Ex_lw(TKo_env, pva, pva, pv_env); xwd <- WD_X_check(pva, pv_env) \#--------Module_4

\# Radiant exergy output

X_out_rad <- fcl * hr * (TKcl_n - TKo_env $) \wedge 2$ / (TKcl_n + TKo_env); xwc $<-$ WC_X_check(TKcl_n, TKo_env)

\# Exergy transfer by convection

X_out_conv $<-\mathrm{fcl} * \mathrm{hc} *\left(\mathrm{TKcl} \_n-\mathrm{TKa}\right) *(1 .-$ TKo_env / TKcl_n $)$; xwc $<-$ WC_X_check(TKcl_n, TKo_env)

Xout_total <- X_st_core + X_st_shell + X_exhale_wc + X_exhale_wd + X_sweat_wc + X_sweat_wd + X_out_rad + X_out_conv

X_consumption $<<-$ Xin_total - Xout_total

ET_star $<<$ - fctET(top, ta, phia, w, im, 50, im); \#--------Module_4

jcount $<-$ jcount +1 ;

tcr $<-$ tcr_n

tsk $<-$ tsk_n

\# Output values

\# Exergy input

XinMETu[i] <- X_met \#metabolism

XinMETwcu[i] <- X_metwc \#metabolism warm/cold

XinAIRwcu[i] <- X_inhale_wc \# inhaled humid air

XinAIRwcwcu[i] <- X_inhale_wcwc

XinAIRwdu[i] <- X_inhale_wd \#

XinAIRwdwdu[i] <- X_inhale_wdwd \# wet/dry

XinLUNGwcu[i] <- X_lw_core_wc \# water lung

XinLUNGwcwcu[i] <- X_lw_core_wcwc

XinLUNGwdu[i] <- X_lw_core_wet

XinLUNGwdwdu[i] <- X_lw_core_wetwd

XinSHELLwcu[i] <- X_lw_shell_wc \# water sweat

XinSHELLwcwcu[i] <- X_lw_shell_wcwc

XinSHELLwdu[i] <- X_lw_shell_wd

XinSHELLwdwdu[i] <- X_lw_shell_wdwd

XinRADu[i] <- X_in_rad \# radiation in

XinRADwcu[i] <- X_in_radwc

XinTOTALu[i] <- Xin_total \# TOTAL exergy input 


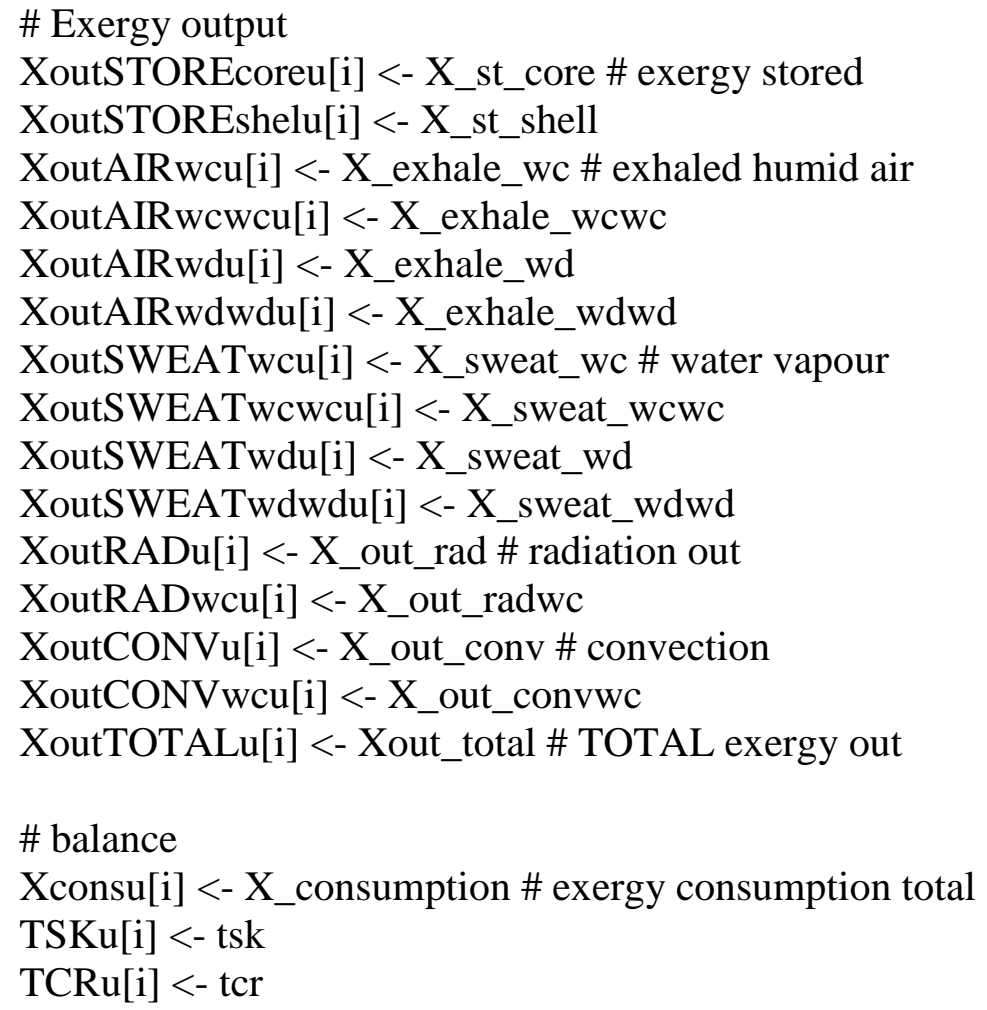


XoutAIRwcu, \# exhaled humid air

XoutAIRwcwcu,

XoutAIRwdu,

XoutAIRwdwdu,

XoutSWEATwcu, \# water vapour

XoutSWEATwcwcu,

XoutSWEATwdu,

XoutSWEATwdwdu,

XoutRADu, \# radiation out

XoutRADwcu,

XoutCONVu, \# convection

XoutCONVwcu,

XoutTOTALu, \# TOTAL exergy out

\# balance

Xconsu, \# exergy consumption total

TSKu,

TCRu,

stringsAsFactors $=$ FALSE

\} \# end of main program

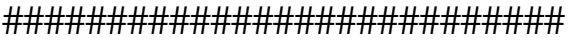


Appendix B. Means and standard deviations of vote means for ramp data

\begin{tabular}{|c|c|c|c|c|c|c|c|c|c|c|c|c|}
\hline $\begin{array}{c}\text { Sessio } \\
\mathrm{n}\end{array}$ & Study & Vote & TSV & Toin & Rhin & & AV & Tout & & Rhout & CLO & Ex \\
\hline $\mathrm{R}$ & $\lg b$ & 3 & $1 \pm 0,71$ & $28,3 \pm 0,33$ & $51,6 \pm 1,4$ & $0 \pm$ & 0 & $8,3 \pm$ & 9 & $70,4 \pm 15$ & $0,5 \pm 0^{1)}$ & $2 \pm 0,11$ \\
\hline $\mathrm{R}$ & $\operatorname{lgb}$ & 4 & $1,7 \pm 0,57$ & $31,3 \pm 0,51$ & $51,9 \pm 0,89$ & $0 \pm$ & 0 & $8,1 \pm$ & 9,1 & $69,6 \pm 16$ & $0,5 \pm 0$ & $2,2 \pm 0,09$ \\
\hline $\mathrm{R}$ & $\operatorname{lgb}$ & 5 & $2,1 \pm 0,59$ & $33 \pm 0,61$ & $52 \pm 0,97$ & $0 \pm$ & 0 & $9,1 \pm$ & 9,4 & $68,3 \pm 16$ & $0,5 \pm 0$ & $2,2 \pm 0,078$ \\
\hline $\mathrm{R}$ & $\lg b$ & 6 & $2,5 \pm 0,47$ & $35 \pm 0,24$ & $50,1 \pm 2,2$ & $0 \pm$ & 0 & $8,7 \pm$ & 9,2 & $68,4 \pm 16$ & $0,5 \pm 0$ & $2,5 \pm 0,26$ \\
\hline $\mathrm{F}$ & p2 & 3 & $-0,6 \pm 0,69$ & $19,8 \pm 0,073$ & $64,3 \pm 2,2$ & $0 \pm$ & 0,017 & $1,4 \pm$ & 3,2 & $81,1 \pm 16$ & $0,8 \pm 0,2$ & $2,7 \pm 0,1$ \\
\hline $\mathrm{F}$ & p2 & 4 & $-0,4 \pm 0,74$ & $20 \pm 0,052$ & $63,8 \pm 1,2$ & $0 \pm$ & 0,013 & $1,4 \pm$ & 3,2 & $81,1 \pm 16$ & $0,8 \pm 0,2$ & $2,6 \pm 0,1$ \\
\hline $\mathrm{F}$ & p2 & 5 & $-0,6 \pm 0,57$ & $20,3 \pm 0,069$ & $62,4 \pm 0,81$ & $0 \pm$ & 0,0097 & $1,6 \pm$ & 2,6 & $77,5 \pm 18$ & $0,8 \pm 0,2$ & $2,5 \pm 0,094$ \\
\hline $\mathrm{F}$ & p2 & 6 & $-0,5 \pm 0,61$ & $20,5 \pm 0,074$ & $61,6 \pm 0,49$ & $0 \pm$ & 0,011 & $1,6 \pm$ & 2,6 & $77,5 \pm 18$ & $0,8 \pm 0,2$ & $2,5 \pm 0,1$ \\
\hline $\mathrm{F}$ & p2 & 7 & $-0,7 \pm 0,74$ & $20,8 \pm 0,069$ & $61 \pm 0,65$ & $0 \pm$ & 0,02 & $2,1 \pm$ & 2,5 & $75,6 \pm 16$ & $0,8 \pm 0,2$ & $2,5 \pm 0,1$ \\
\hline $\mathrm{F}$ & p2 & 8 & $-0,6 \pm 0,56$ & $21 \pm 0,11$ & $59,6 \pm 1$ & $0 \pm$ & 0,014 & $2,1 \pm$ & 2,5 & $75,6 \pm 16$ & $0,8 \pm 0,2$ & $2,5 \pm 0,12$ \\
\hline $\mathrm{F}$ & p2 & 9 & $-0,4 \pm 0,49$ & $21,4 \pm 0,073$ & $58,8 \pm 0,85$ & $0 \pm$ & 0,018 & $2,4 \pm$ & 2,7 & $71,8 \pm 16$ & $0,8 \pm 0,2$ & $2,4 \pm 0,12$ \\
\hline$F$ & p2 & 10 & $-0,2 \pm 0,58$ & $21,6 \pm 0,16$ & $53,2 \pm 9$ & $0 \pm$ & 0,015 & $1,2 \pm$ & 0,92 & $64,8 \pm 9$ & $0,7 \pm \begin{array}{l}0,1 \\
6\end{array}$ & $2,4 \pm 0,25$ \\
\hline $\mathrm{F}$ & p2 & 11 & $-0,1 \pm 0,57$ & $22 \pm 0,047$ & $50,6 \pm 12$ & $0,1 \pm$ & 0,029 & \pm & 0,75 & $67,7 \pm 7,9$ & $0,7 \pm \begin{array}{l}0,1 \\
6\end{array}$ & $2,4 \pm 0,31$ \\
\hline $\mathrm{F}$ & p2 & 12 & $-0,2 \pm 0,65$ & $22,2 \pm 0,04$ & $49,5 \pm 13$ & $0 \pm$ & 0,029 & \pm & 0,75 & $67,7 \pm 7,9$ & $0,7 \pm \begin{array}{l}0,1 \\
6\end{array}$ & $2,4 \pm 0,33$ \\
\hline $\mathrm{F}$ & p2 & 13 & $-0,1 \pm 0,76$ & $22,6 \pm 0,068$ & $48,3 \pm 13$ & $0 \pm$ & 0,0051 & $0,7 \pm$ & 0,99 & $75,5 \pm 13$ & $0,7 \pm \begin{array}{l}0,1 \\
6\end{array}$ & $2,4 \pm 0,36$ \\
\hline $\mathrm{F}$ & $\mathrm{p} 2$ & 14 & $0 \pm 0,67$ & $22,9 \pm 0,053$ & $49,5 \pm 12$ & $0 \pm$ & 0,014 & $2,1 \pm$ & 2,9 & $80,4 \pm 15$ & $0,8 \pm 0,2$ & $2,4 \pm 0,35$ \\
\hline$F$ & p2 & 15 & $0,1 \pm 0,66$ & $23,2 \pm 0,054$ & $48,7 \pm 12$ & $0 \pm$ & 0,02 & $2,5 \pm$ & 3,8 & $80,3 \pm 16$ & $0,8 \pm 0,2$ & $2,4 \pm 0,37$ \\
\hline$F$ & p2 & 16 & $0,2 \pm 0,64$ & $23,4 \pm 0,074$ & $47,4 \pm 12$ & $0 \pm$ & 0,014 & $2,5 \pm$ & 3,8 & $80,3 \pm 16$ & $0,8 \pm 0,2$ & $2,4 \pm 0,38$ \\
\hline $\mathrm{F}$ & p2 & 17 & $0,1 \pm 0,54$ & $23,7 \pm 0,019$ & $46,2 \pm 12$ & $0 \pm$ & 0,013 & $2,8 \pm$ & 4,6 & $80,6 \pm 16$ & $0,8 \pm 0,2$ & $2,4 \pm 0,4$ \\
\hline G & p2 & 3 & $-0,8 \pm 0,67$ & $19,4 \pm 0,44$ & $67,1 \pm 1,6$ & $0 \pm$ & 0,0083 & $1,5 \pm$ & 4,7 & $83,8 \pm 6,9$ & $0,7 \pm \begin{array}{l}0,1 \\
7\end{array}$ & $2,7 \pm 0,061$ \\
\hline G & p2 & 4 & $-0,6 \pm 0,57$ & $19,6 \pm 0,62$ & $63,9 \pm 4,5$ & $0 \pm$ & 0,0083 & $1,5 \pm$ & 4,7 & $83,8 \pm 6,9$ & $0,7 \pm \begin{array}{l}0,1 \\
7\end{array}$ & $2,7 \pm 0,058$ \\
\hline G & p2 & 5 & $-0,7 \pm 0,56$ & $20 \pm 0,092$ & $63,3 \pm 1,5$ & $0,1 \pm$ & 0,019 & $2,1 \pm$ & 4,1 & $78,2 \pm 12$ & $0,7 \pm \begin{array}{l}0,1 \\
7\end{array}$ & $2,6 \pm 0,15$ \\
\hline G & p2 & 6 & $-0,4 \pm 0,47$ & $20,6 \pm 0,078$ & $61,6 \pm 0,5$ & $0 \pm$ & 0,026 & $2,1 \pm$ & 4,1 & $78,2 \pm 12$ & $0,7 \pm \begin{array}{l}0,1 \\
7\end{array}$ & $2,5 \pm 0,11$ \\
\hline G & p2 & 7 & $-0,6 \pm 0,66$ & $21,3 \pm 0,044$ & $59,2 \pm 1,1$ & $0 \pm$ & 0,019 & $2,5 \pm$ & 3,9 & $76,3 \pm 15$ & $0,7 \pm \begin{array}{l}0,1 \\
7\end{array}$ & $2,4 \pm 0,1$ \\
\hline G & p2 & 8 & $-0,2 \pm 0,61$ & $21,8 \pm 0,045$ & $57,8 \pm 0,81$ & $0 \pm$ & 0,012 & $2,5 \pm$ & 4 & $77 \pm 15$ & $0,7 \pm \begin{array}{l}0,1 \\
7\end{array}$ & $2,3 \pm 0,11$ \\
\hline G & $\mathrm{p} 2$ & 9 & $0,1 \pm 0,53$ & $22,5 \pm 0,05$ & $55,5 \pm 0,6$ & $0 \pm$ & 0,032 & $2,4 \pm$ & 4,1 & $76,6 \pm 19$ & $0,7 \pm \begin{array}{l}0,1 \\
7\end{array}$ & $2,3 \pm 0,1$ \\
\hline G & p2 & 10 & $0,1 \pm 0,46$ & $22,9 \pm 0,025$ & $53,4 \pm 0,51$ & $0 \pm$ & 0,021 & $2,4 \pm$ & 4,1 & $76,6 \pm 19$ & $0,7 \pm \begin{array}{l}0,1 \\
7\end{array}$ & $2,2 \pm 0,12$ \\
\hline G & p2 & 11 & $0,2 \pm 0,46$ & $23,7 \pm 0,035$ & $51,2 \pm 0,44$ & $0 \pm$ & 0,0073 & $2,4 \pm$ & 4 & $76,7 \pm 18$ & $0,7 \pm \begin{array}{l}0,1 \\
7\end{array}$ & $2,2 \pm 0,12$ \\
\hline G & p2 & 12 & $0,3 \pm 0,56$ & $24,1 \pm 0,04$ & $49,5 \pm 0,51$ & $0 \pm$ & 0,012 & $2,4 \pm$ & 4 & $76,6 \pm 18$ & $0,7 \pm \begin{array}{l}0,1 \\
7\end{array}$ & $2,2 \pm 0,13$ \\
\hline G & p2 & 13 & $0,5 \pm 0,56$ & $24,8 \pm 0,059$ & $48 \pm 0,74$ & $0 \pm$ & 0,012 & $2,3 \pm$ & 3,6 & $75,8 \pm 20$ & $0,7 \pm \begin{array}{l}0,1 \\
7\end{array}$ & $2,2 \pm 0,17$ \\
\hline $\mathrm{H}$ & p2 & 3 & $0,5 \pm 0,54$ & $23,5 \pm 0,19$ & $51,5 \pm 0,76$ & $0 \pm$ & 0,0054 & $0,6 \pm$ & 4 & $85,6 \pm 7,6$ & $0,7 \pm \begin{array}{l}0,1 \\
9\end{array}$ & $2,4 \pm 0,12$ \\
\hline $\mathrm{H}$ & p2 & 4 & $0,4 \pm 0,64$ & $23,3 \pm 0,24$ & $52,1 \pm 0,65$ & $0 \pm$ & 0,013 & $0,6 \pm$ & 4 & $85,5 \pm 7,7$ & $0,7 \pm \begin{array}{l}0,1 \\
9\end{array}$ & $2,4 \pm 0,12$ \\
\hline $\mathrm{H}$ & p2 & 5 & $0,2 \pm 0,4$ & $22,8 \pm 0,073$ & $53,4 \pm 1,4$ & $0 \pm$ & 0,0068 & $1,3 \pm$ & 3,9 & $85,2 \pm 8,9$ & $0,7 \pm \begin{array}{l}0,1 \\
9\end{array}$ & $2,4 \pm 0,12$ \\
\hline $\mathrm{H}$ & p2 & 6 & $0,1 \pm 0,24$ & $22,6 \pm 0,045$ & $53,8 \pm 0,37$ & $0 \pm$ & 0,015 & $1,3 \pm$ & 3,9 & $85,2 \pm 8,9$ & $0,7 \pm \begin{array}{l}0,1 \\
9\end{array}$ & $2,4 \pm 0,094$ \\
\hline $\mathrm{H}$ & p2 & 7 & $0 \pm 0,36$ & $22,3 \pm 0,062$ & $55,6 \pm 0,5$ & $0 \pm$ & 0,011 & $1,6 \pm$ & 3,7 & $83,5 \pm 9,4$ & $0,7 \pm \begin{array}{l}0,1 \\
9\end{array}$ & $2,4 \pm 0,094$ \\
\hline $\mathrm{H}$ & p2 & 8 & $-0,1 \pm 0,37$ & $22,1 \pm 0,051$ & $56 \pm 0$ & $0 \pm$ & 0,0096 & $1,6 \pm$ & 3,7 & $83,5 \pm 9,4$ & $0,7 \pm \begin{array}{l}0,1 \\
9\end{array}$ & $2,4 \pm 0,089$ \\
\hline $\mathrm{H}$ & p2 & 9 & $-0,2 \pm 0,46$ & $21,8 \pm 0,05$ & $57,2 \pm 0,49$ & $0 \pm$ & 0,019 & 2 & 3,6 & $79,6 \pm 11$ & $0,7 \pm \begin{array}{l}0,1 \\
9\end{array}$ & $2,5 \pm 0,094$ \\
\hline
\end{tabular}




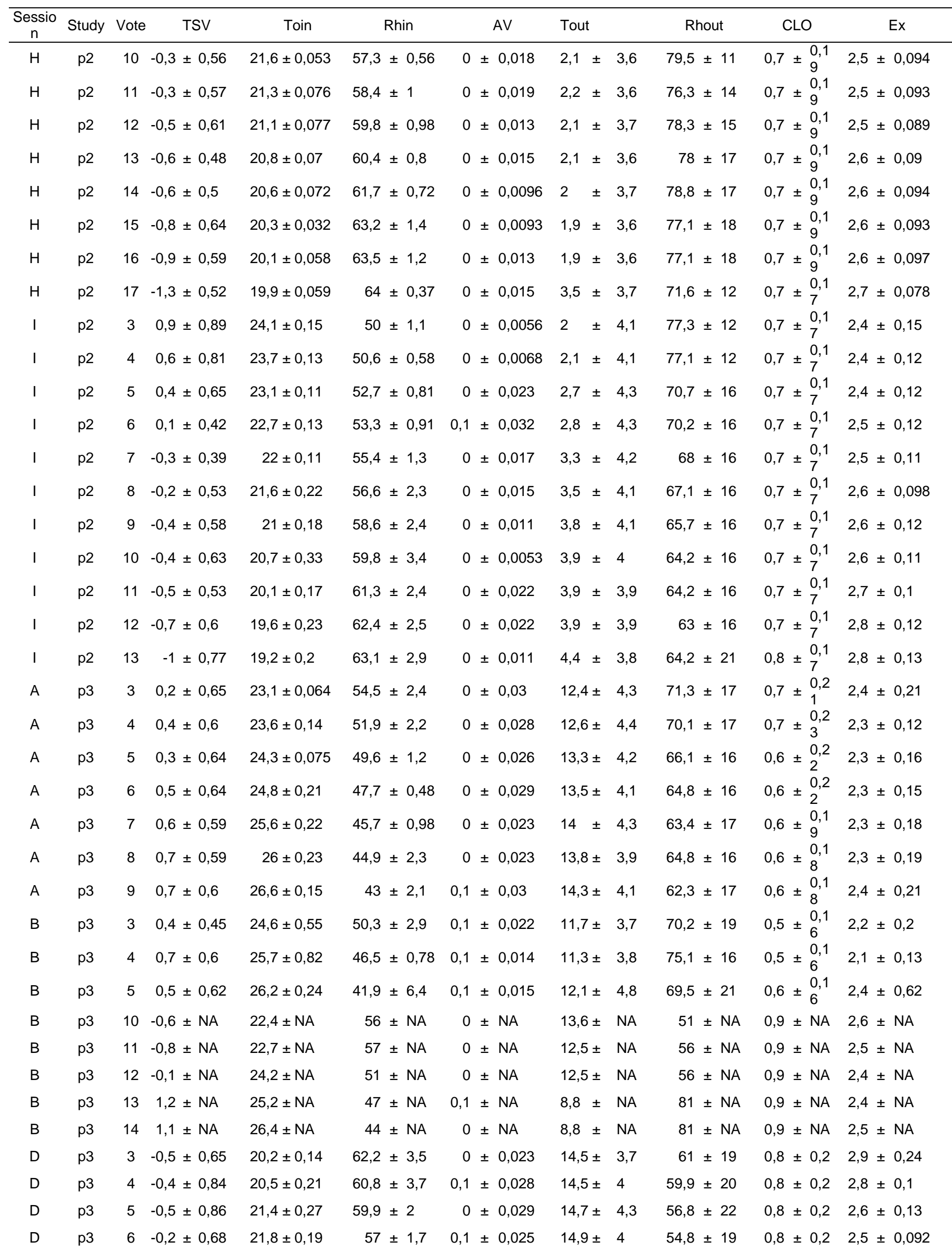




\begin{tabular}{|c|c|c|c|c|c|c|c|c|c|c|c|c|}
\hline $\begin{array}{c}\text { Sessio } \\
\mathrm{n}\end{array}$ & Study & Vote & TSV & Toin & Rhin & & AV & Tout & & Rhout & CLO & Ex \\
\hline $\mathrm{D}$ & p3 & 7 & $-0,2 \pm 0,81$ & $22,5 \pm 0,27$ & $54,5 \pm 0,98$ & 0,1 & $\pm 0,026$ & $15,2 \pm$ & 4,2 & $53,9 \pm 20$ & $0,8 \pm 0,2$ & $2,5 \pm 0,12$ \\
\hline D & p3 & 8 & $0 \pm 0,73$ & $22,8 \pm 0,28$ & $53,8 \pm 0,9$ & 0,1 & $\pm 0,027$ & $14,8 \pm$ & 4 & $53,7 \pm 18$ & $0,8 \pm 0,2$ & $2,5 \pm 0,13$ \\
\hline D & p3 & 9 & $0 \pm 0,82$ & $23,2 \pm 0,38$ & $51,8 \pm 1$ & 0,1 & $\pm 0,031$ & $15,1 \pm$ & 4,1 & $53,3 \pm 18$ & $0,7 \pm \begin{array}{l}0,2 \\
2\end{array}$ & $2,5 \pm 0,15$ \\
\hline$E$ & p3 & 3 & $0 \pm 0,67$ & $23,1 \pm 0,17$ & $53,1 \pm 1,1$ & 0 & $\pm 0,024$ & $13,6 \pm$ & 4,6 & $68,5 \pm 19$ & $0,6 \pm \begin{array}{l}0,2 \\
2\end{array}$ & $2,8 \pm 0,69$ \\
\hline$E$ & p3 & 4 & $0,1 \pm 0,58$ & $22,7 \pm 0,19$ & $54,1 \pm 1$ & 0,1 & $\pm 0,024$ & $13,5 \pm$ & 4,6 & $65,9 \pm 21$ & $0,6 \pm \begin{array}{l}0,2 \\
1\end{array}$ & $2,6 \pm 0,41$ \\
\hline$E$ & p3 & 5 & $-0,4 \pm 0,62$ & $22 \pm 0,17$ & $56,6 \pm 2,2$ & 0,1 & $\pm 0,023$ & $13,7 \pm$ & 4,4 & $64,4 \pm 20$ & $0,7 \pm 0,2$ & $2,5 \pm 0,18$ \\
\hline$E$ & p3 & 6 & $-0,4 \pm 0,95$ & $21,4 \pm 0,55$ & $55,9 \pm 2,1$ & 0,1 & $\pm 0,021$ & $13,7 \pm$ & 4,5 & $63,4 \pm 20$ & $0,7 \pm 0,2$ & $2,6 \pm 0,27$ \\
\hline$E$ & p3 & 7 & $-0,7 \pm 0,88$ & $20,4 \pm 1,5$ & $60,9 \pm 4,5$ & 0,1 & $\pm 0,015$ & $13,8 \pm$ & 4,4 & $63,1 \pm 20$ & $0,8 \pm \begin{array}{l}0,2 \\
1\end{array}$ & $2,7 \pm 0,35$ \\
\hline$E$ & p3 & 8 & $-0,7 \pm 0,83$ & $20,5 \pm 0,8$ & $60,9 \pm 2,2$ & 0,1 & $\pm 0,024$ & $13,5 \pm$ & 4,4 & $64,5 \pm 19$ & $0,8 \pm \begin{array}{l}0,2 \\
1\end{array}$ & $2,6 \pm 0,24$ \\
\hline$E$ & p3 & 9 & $-0,9 \pm 0,97$ & $19,9 \pm 0,86$ & $60,2 \pm 3,2$ & 0,1 & $\pm 0,02$ & $13,7 \pm$ & 4,2 & $63,5 \pm 18$ & $0,7 \pm \begin{array}{l}0,2 \\
5\end{array}$ & $2,9 \pm 0,15$ \\
\hline
\end{tabular}

1) In this study, clothing was not included in the questionnaire, because the subjects were wearing standardized clothing levels. 